\title{
LA ESCLAVITUD SEXUAL EN LA LEGISLACIÓN PENAL COLOMBIANA. INTERPRETACIÓN A TRAVÉS DE OTRAS FUENTES NORMATIVAS Y JURISPRUDENCIALES
}

\section{Claudia Marcela Páez Bravo}

Maestría en Derechos Humanos y Democratización (C), Universidad de San Martín, Argentina; Abogada Universidad Industrial de Santander, $(\mathrm{Col})$; Abogada e investigadora de la Corporación Alianza Iniciativa de Mujeres Colombianas por la Paz (Col).

E-mail:marcelapaez@gmail.com

\begin{abstract}
Resumen
El artículo 141 del Código Penal Colombiano penaliza a quienes, con ocasión y en desarrollo del conflicto armado, obligan a personas protegidas por el derecho internacional humanitario a prestar servicios sexuales. Dicha norma homologa bajo una misma descripción típica las conductas de prostitución forzada y esclavitud sexual, pese a que se tratan de conductas con elementos constitutivos diversos, a la luz de la normativa y jurisprudencia internacionales. Luego de establecer la validez de diversas fuentes foráneas de derecho, se recurre a ellas para determinar la definición de estas conductas y el consecuente alcance del mencionado artículo 141, concluyendo que con base en el mismo puede castigarse tanto la esclavitud sexual como la prostitución forzada.
\end{abstract}

\section{Palabras clave}

Esclavitud sexual, prostitución forzada, conflicto armado, derecho internacional humanitario, bloque de constitucionalidad, ius cogens.

\begin{abstract}
The Article 141 of the Colombian Criminal Law penalizes those who, with occasion and during the development of an armed conflict, force people protected by the international humanitarian law to give sexual services. This norm ratifies under the same typical description the criminal conducts of forced prostitution and sexual slavery, even though they are conducts with diverse constitutive elements in the eyes of international law and jurisprudence. After establishing the validity of diverse international sources of law, they will be used to determine the definition of these conducts and the extent of its consequence in the art. 141, concluding that with the same norm the criminal conduct of sexual slavery and forced prostitution can be punished.
\end{abstract}

\section{Key Words}

Sexual slavery, forced prostitution, armed conflict, international humanitarian law, constitucional block, ius cogens 

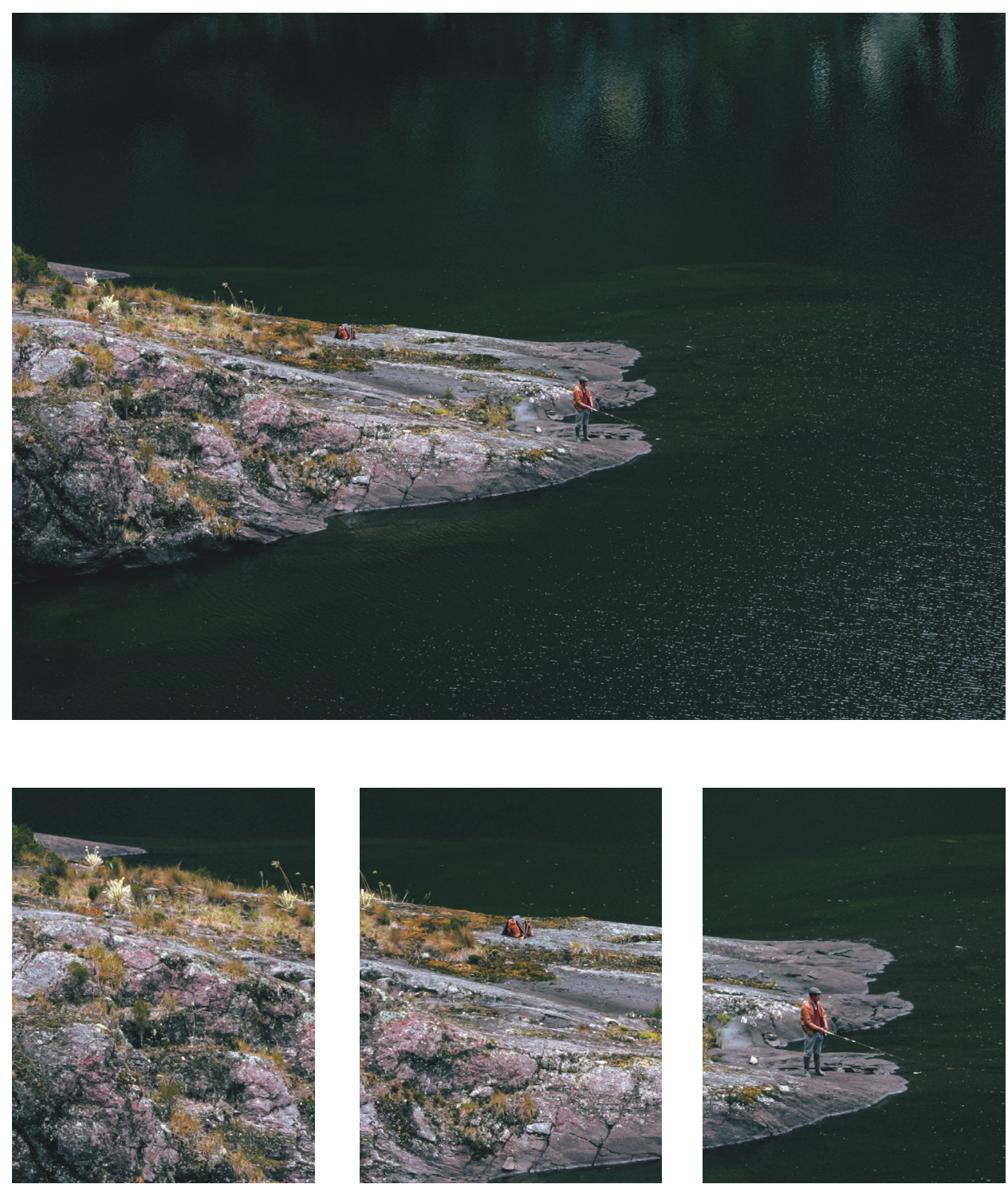

El pescador en la "Laguna del Potrero" 


\section{LA ESCLAVITUD SEXUAL EN LA LEGISLACIÓN PENAL COLOMBIANA. INTERPRETACIÓN A TRAVÉS DE OTRAS FUENTES NORMATIVAS Y JURISPRUDENCIALES*}

Claudia Marcela Páez Bravo

El Título II del Libro $2^{\circ}$ del Código Penal incorporó al derecho interno la sanción de algunas infracciones a la normativa de derecho internacional humanitario vinculante para el estado colombiano, penalizando diversas conductas cometidas con ocasión y en desarrollo del conflicto armado que atentan contra personas y bienes protegidos por la normativa humanitaria.

En particular, el artículo 141 sanciona la prostitución forzada o esclavitud sexual. Dicha norma equipara bajo una misma descripción típica estas dos conductas, definiéndolas como la prestación forzosa de servicios sexuales.

El texto pretende determinar el alcance de la norma penal aludida, recurriendo en primer lugar al derecho interno y posteriormente examinando diversas fuentes normativas y jurisprudenciales internacionales, luego de establecer la validez de las mismas como fuentes de interpretación.

\section{La incorporación del derecho internacional humanitario al ordenamiento interno}

El Derecho Internacional Humanitario tiene como fin la humanización de los conflictos armados, es decir, la preservación de la dignidad humana durante los

El artículo es producto del informe final de la investigación: Litigio de casos de violencia sexual perpetrados en contextos de conflicto armado, desarrollado en la Corporación Alianza Iniciativa de Mujeres Colombianas por la Paz (Col). 
mismos. En este sentido, su normativa procura el respeto de unos derechos mínimos e inderogables que cobijan tanto a combatientes como a no combatientes (de manera diferenciada), y que en términos generales, pretende establecer un equilibrio entre necesidades militares y el principio de humanidad, con el objeto de disminuir las hostilidades, minimizar los efectos sobre la población civil y sus bienes, y garantizar un trato humanitario a combatientes, heridos y prisioneros. ${ }^{1}$

Las normas que lo integran se estructuran, a la vez, como un conjunto de disposiciones mediante las cuales se reconocen a las personas unos derechos inherentes a su dignidad, y asimismo, como un elenco de prohibiciones cuyo desconocimiento puede comprometer la responsabilidad penal internacional de sus infractores ${ }^{2}$, integrando de esta manera un catálogo axiológico cuya validez absoluta $y$ universal no depende de su consagración en el ordenamiento positivo ${ }^{3}$. No obstante, la garantía de estos derechos y la eficacia de estas prohibiciones, dependen de la adecuación del ordenamiento interno de los Estados a la luz de esta normativa, y particularmente, de la adopción de medidas de carácter penal o disciplinario que sancionen las violaciones a dichas normas internacionales. ${ }^{4}$

Lo anterior se debe a que muchas de las disposiciones que integran el derecho internacional humanitario no tienen carácter de autoejecutivas (non-self-executing); esto implica que para crear derechos y establecer obligaciones aplicables al interior de los Estados e invocables ante sus tribunales, requieren de un desarrollo legislativo en los ordenamientos jurídicos nacionales.

Tal como lo afirma la Corte Constitucional, “(...) este es, precisamente, el caso de un importante número de prohibiciones que aparecen consignadas en diversos instrumentos internacionales (vgr. Artículo 3 común a los cuatro Convenios de Ginebra de 1949), las cuales requieren de una disposición legal que las desarrolle, para efectos de tipificar un determinado comportamiento como delito o sanción disciplinaria (...)". 5

El derecho internacional no impone a los Estados un determinado mecanismo o procedimiento a través del cual ha de ser incorporada su normativa en los

1 Salmón, Elizabeth. Introducción al Derecho Internacional Humanitario. Instituto de Democracia y Derechos Humanos de la Pontificia Universidad Católica del Perú y Comité Internacional de la Cruz Roja. Fondo Editorial de la Pontificia Universidad Católica del Perú, 2004.

2 Corte Constitucional, Sentencia C-1076 de 2002. M.P. Clara Inés Vargas Hernández.

3 Corte Constitucional, Sentencia C-574 de 1992. M.P. Ciro Angarita Barón.

4 Corte Constitucional, Sentencia C-1076 de 2002. M.P. Clara Inés Vargas Hernández.

$5 \quad$ Ibid. En este sentido, los artículos 49 del Convenio I, 50 del Convenio II, 146 del Convenio IV y 86 del Protocolo I, estipulan la obligación de los Estados contratantes de tomar todas las oportunas medidas legislativas para determinar las adecuadas sanciones penales que se han de aplicar a las personas que hayan cometido, o dado orden de com eter, una cualquiera de las infracciones graves contra dichos Convenios. 
ordenamientos internos. No obstante, dicha incorporación debe realizarse atendiendo a lo dispuesto en los artículos 26 y 27 de la Convención de Viena sobre el Derecho de los Tratados, que consagran la obligación de los Estados de cumplir, de buena fe, los compromisos adquiridos, y la prohibición de invocar disposiciones de su derecho interno como justificación del incumplimiento de sus obligaciones internacionales. En este sentido, afirma la Corte Constitucional que "si bien los derechos no deben ser traducidos literalmente a leyes internas, ni en los Convenios se aconsejan procedimientos determinados para invocarlos en los sistemas domésticos, el Estado debe asegurarse de que la organización o la legislación locales prevean mecanismos efectivos de protección de los derechos consagrados en los instrumentos."

En este sentido, la Corte Constitucional ha sostenido que la obligación general de respetar y hacer respetar el derecho internacional humanitario se manifiesta en varios deberes específicos, entre los que se encuentra el de investigar, juzgar, sancionar y reparar los crímenes de guerra, los crimenes de lesa humanidad y el genocidio cometidos en el curso de conflictos armados internos, el cual a su vez comprende el deber de adoptar al nivel de derecho interno los actos de tipo legislativo, administrativo o judicial necesarios para adaptar el ordenamiento jurídico doméstico a las pautas establecidas, en lo aplicable, por el derecho humanitario ${ }^{7}$.

En desarrollo de estos deberes, el Constituyente de 1991 incorporó el derecho internacional humanitario al bloque de constitucionalidad, a través del artículo 214 numeral $2^{\circ}$ de la Carta, en el cual se consagró el valor supraconstitucional del derecho internacional humanitario cuando, al regular los parámetros a que se sujetan las atribuciones presidenciales durante los estados de excepción, dispuso que: "En todo caso se respetarán las reglas del derecho internacional humanitario". ${ }^{\circ}$

Asimismo, el artículo 93 constitucional consagró la primacía del derecho internacional convencional relativo a los derechos humanos, al establecer la prevalencia de los tratados y convenios ratificados por Colombia y la obligación de interpretar la Carta de derechos de conformidad con dichos convenios y tratados. ${ }^{9}$

Más allá de la adhesión del Estado colombiano a los instrumentos internacionales de derecho humanitario ${ }^{10}$, a la luz de estas disposiciones y atendiendo al carácter

6 Corte Constitucional, Sentencia T-568 de 1999. M.P. Carlos Gaviria Díaz.

7 Ibid.

8 Corte Constitucional, Sentencia C-574 de 1992. M.P. Ciro Angarita Barón.

9 Ibid.

10 Colombia es parte de los cuatro Convenios de Ginebra de 1949, aprobados mediante la Ley $5^{\text {a }}$ de 1960, y vigentes desde el 8 de mayo de 1962. Igualmente, mediante Ley 11 de 1992 se aprobó el Protocolo Adicional I, mientras que el Protocolo Adicional II fue aprobado mediante Ley 171 de 1994. 
de ius cogens de la normativa humanitaria ${ }^{11}$, el Constituyente acogió la fórmula de incorporación automática del derecho internacional humanitario al ordenamiento nacional. ${ }^{12}$ No obstante, en reciente jurisprudencia ${ }^{13}$, la Corte Constitucional ha sostenido que no todas las disposiciones que integran esta normativa hacen parte del ius cogens; afirmando que solo gozan de esta calidad los principios esenciales de distinción, precaución y el principio humanitario, y las garantías fundamentales que de ellos derivan, entre las cuales se encuentran:

(...) (vi) la prohibición de la violencia de género, de la violencia sexual, de la prostitución forzada y de los atentados contra el pudor;

(vii) la prohibición de la esclavitud y de la trata de esclavos -norma con rango propio de ius cogens-;

(viii) la prohibición del trabajo forzado no retribuido o abusivo;

$(\ldots)^{14}$

No obstante lo anterior, la incorporación automática del derecho internacional humanitario al ordenamiento nacional a través de su integración al bloque de constitucionalidad, no agota el deber de adaptar el derecho interno a esta normativa. Por el contrario, la Corte Constitucional ha dispuesto que:

“(...) la imperatividad de las normas humanitarias y su integración en el bloque de constitucionalidad implica que el Estado colombiano debe adaptar las normas de inferior jerarquía del orden jurídico interno a los contenidos del derecho internacional humanitario, con el fin de potenciar la realización material de tales valores." 15

En este mismo sentido, ha establecido la Corte Suprema de Justicia que:

“(...) es obligación del Estado colombiano garantizar que las violaciones graves al derecho internacional humanitario sean castigadas como lo que son, esto es, como atentados que no solo afectan la vida, la integridad física, la dignidad, la libertad de las personas, entre otros bienes relevantes, sino que atentan contra valores fundamentales reconocidos por la humanidad

11 La Corte Constitucional, en sentencia C-574/92 afirmó que "los principios del derecho internacional humanitario plasmados en los Convenios de Ginebra y en sus dos Protocolos, por el hecho de constituir un catálogo mínimo aplicable a situaciones de conflicto nacional o internacional, ampliamente aceptado por la comunidad internacional, hacen parte del ius cogens o derecho consuetudinario de los pueblos". En igual sentido, Sentencia C-225 de 1995.

12 Corte Constitucional, Sentencia C-574 de 1992, M.P. Ciro Angarita Barón y Corte Suprema de justicia, Sala de Casación Penal, Auto con radicado No. 32.022, del 21 septiembre de 2009, M.P. Sigifredo Espinosa Pérez.

13 Corte Constitucional, Sentencia C-291 de 2007. M.P. Manuel José Cepeda Espinosa.

14 Ibid.

15 Corte Constitucional, Sentencia C-574 de 1992. M.P. Ciro Angarita Barón. Ello es reiterado en las sentencias C-225 de 1995 y T-568 de 1999. 
entera y compilados en el conjunto de normas que conforman el llamado derecho internacional humanitario" ${ }^{\prime \prime 6}$.

La incorporación del Título II del Libro $2^{\circ}$ del Código Penal (Ley 599 de 2000), a través de la cual se tipifican como delitos en nuestra legislación interna las infracciones graves contra las personas y bienes protegidos por el derecho internacional humanitario, da cumplimiento a lo dispuesto en las sentencias previamente citadas, así como a lo estipulado en la normativa humanitaria en relación con la obligación de adoptar medidas legislativas para establecer sanciones penales adecuadas a sus infractores ${ }^{17}$.

De esta manera, el Título II constituye el marco normativo a través del cual las autoridades judiciales pueden investigar y sancionar los crímenes internacionales en el ámbito interno. Por su parte, en virtud del artículo 93 de la Carta Política, el derecho internacional humanitario se erige como fuente de interpretación de los delitos incorporados en dicho título, fundamentalmente a la hora de dar contenido a algunos ingredientes normativos.

Lo anterior tiene especial relevancia (como se verá más adelante), teniendo en cuenta que las conductas penalizadas en el Título II contemplan elementos cuyo contenido no ha sido previsto expresamente en la descripción típica, siendo necesario acudir a otras fuentes normativas para integrarlos. Estos elementos generalmente se refieren a expresiones propias del derecho internacional humanitario, por lo cual es necesario recurrir a sus normas y principios como fuente de interpretación.

\section{La esclavitud sexual a la luz del derecho interno}

La prohibición de la esclavitud tiene el rango de norma de ius $\operatorname{cogens}^{18}$ y como tal, es incorporada constitucionalmente a través del artículo 17 de la Carta Política, el cual estipula que:

"Se prohíben la esclavitud, la servidumbre y la trata de seres humanos en todas sus formas."

Por su parte, la Ley 599 de 2000 incorpora la prohibición de aquellos actos de esclavitud que involucran además la prestación de servicios sexuales, cuando la

16 Corte Suprema de justicia, Sala de Casación Penal, Proceso No. 32.022, auto del 21 septiembre de 2009, M.P. Sigifredo Espinosa Pérez.

17 En este sentido, ver nota al pie No. 5 supra. Adicionalmente, la Corte Suprema de Justicia ha sostenido que la consagración del Título II del Libro $2^{\circ}$ de la Ley 599 de 2000 constituye una "respuesta a la necesidad de brindar un nivel especial de protección a la población civil afectada por la magnitud del conflicto armado que desde décadas atrás se vive en Colombia (...)" (Sala de Casación Penal, Proceso No. 32.022, auto del 21 septiembre de 2009, M.P. Sigifredo Espinosa Pérez).

18 Corte Constitucional, Sentencia C-291 de 2007. M.P. Manuel José Cepeda Espinosa. 
misma es cometida en contextos de conflicto armado, a través del artículo 141, el cual estipula:

Prostitución forzada o esclavitud sexual. El que mediante el uso de la fuerza y con ocasión y en desarrollo del conflicto armado obligue a persona protegida a prestar servicios sexuales incurrirá en prisión (...). (Cursivas fuera del original)

El artículo citado penaliza bajo una misma descripción típica, los delitos de esclavitud sexual y prostitución forzada, consagrando como conducta típica el "obligar a prestar servicios sexuales". Esta definición, en principio, parece más ajustada al concepto de prostitución. Sin embargo, como se expondrá en adelante, la prestación de servicios sexuales es un elemento común a las conductas de esclavitud sexual y prostitución forzada.

En todo caso, la prostitución forzada es una forma de esclavitud sexual, en tanto ambas conductas obeceden a la prestación de servicios sexuales mediante el uso de la fuerza, reduciendo a sus víctimas a la condición de cosas u objetos y anulando su autonomía personal. Sin embargo, la prostitución forzada tiene un elemento en particular que la diferencia de otras modalidades de esclavitud: en ella, el autor u otra persona han debido obtener (o esperan hacerlo), ventajas pecuniarias o de otro tipo a cambio de los servicios sexuales prestados por la víctima.

Ello pemite afirmar que, en principio, la descripción típica del artículo 141 del Código Penal se ajusta a cualquiera de estas dos formas de violencia sexual, pues la prestación forzosa de servicios sexuales se da de igual manera en los dos delitos.

Por ello, resulta fundamental determinar el alcance del tipo penal consagrado en la citada norma.

Sin embargo, más allá del artículo 141 del Código Penal, no existe en la legislación colombiana otra definición de esclavitud sexual que de manera expresa consagre los elementos de esta conducta. Por ello, es necesario examinar otras fuentes-normativas, jurisprudenciales y doctrinarias- que permitan establecer el alcance de este tipo penal. Recurriremos de esta manera, a lo dispuesto en el derecho internacional humanitario, en la Convención sobre la Esclavitud de 1926, en el Estatuto de Roma, y en el informe de la Relatora especial sobre la violación sistemática, la esclavitud sexual y las prácticas análogas de esclavitud en tiempo de conflicto armado, así como a la jurisprudencia de los tribunales internacionales.

\section{La validez de otras normas como fuente de interpretación}

En sentencia C-291 de 2007, la Corte Constitucional afirmó que:

"El Legislador cuenta con un amplio margen de configuración para el diseño de la política criminal y el derecho penal, dentro del cual puede optar por diversas alternativas de regulación que incluyen la potestad de crear los delitos, establecer los elementos constitutivos de los tipos penales y sus correspondientes sanciones, así como el procedimiento a seguir para su 
investigación y juzgamiento; la competencia amplia y exclusiva del Legislador en este ámbito se basa en el principio democrático y en la soberanía popular ${ }^{19}$. Sin embargo, tal potestad legislativa encuentra sus límites en la Constitución Política y en las normas que integran el bloque de constitucionalidad, y corresponde a la Corte Constitucional hacer efectivos dichos limites,

19 En este sentido, en la sentencia C-148 de 2005 se reiteró: "La Corte ha sido enfática en reconocer que para la definición de la política criminal del Estado y, en particular, en materia penal para la configuración de las conductas punibles, el órgano legislativo tiene una competencia amplia y exclusiva que encuentra claro respaldo en el principio democrático y en la soberanía popular (C.P. arts. $1^{\circ}$ y $\left.3^{\circ}\right)$, razón por la cual, corresponde a las mayorías políticas, representadas en el Congreso, determinar, dentro de los marcos de la Constitución Política, la orientación del Estado en estas materias. [Ver en este sentido entre otras las sentencias C-559 de 1999. MP Alejandro Martínez Caballero, C-226/02 M.P. Álvaro Tafur Galvis, C-420/02 M.P. Jaime Córdoba Triviño, C-762/02 M.P. Rodrigo Escobar Gil, C-205/03 M.P. Clara Inés Vargas Hernández.]// Esta circunstancia, permite que el legislador adopte distintas estrategias de política criminal, siempre que la alternativa aprobada, además de ser legítima en cuanto a la forma como se configura, respete los valores, preceptos y principios constitucionales. Así las cosas, es evidente que la política criminal y el derecho penal no se encuentran definidos en el texto constitucional sino que corresponde al legislador desarrollarlos. La Corte ha precisado que en el ejercicio de su atribución el Congreso "no puede desbordar la Constitución y está subordinado a ella porque la Carta es norma de normas (CP art. 4). Pero, en función del pluralismo y la participación democrática, el Legislador puede tomar diversas opciones dentro del marco de la Carta.[ Sentencia C-038 de 1995. Fundamento 4]" // En este sentido es claro para la Corte que la Constitución reconoce al Legislador un margen de discrecionalidad para desarrollar la política criminal y determinar o no el establecimiento de delitos y sanciones según la valoración que este haga en el marco de la Constitución [Al respecto cabe recordar lo dicho por la Corte en la Sentencia C-237/97 en la que se señaló lo siguiente:"El derecho penal, que en un Estado democrático debe ser la última ratio, puede ser utilizado, sin vulnerar la Constitución, para sancionar las conductas lesivas de bienes jurídicos ajenos que se estiman esenciales y cuya vulneración, en consecuencia, debe asociarse a una pena. La Corte, en función de la competencia que le ha sido atribuida, puede valorar la norma atendiendo sólo criterios de razonabilidad y proporcionalidad.."Sentencia C-237/97 M.P. Carlos Gaviria Díaz.]. Ese es el margen de acción de la función legislativa en materia punitiva, en el que si el legislador advierte que la criminalización es la forma más invasiva de control social, por su intensa afectación de la libertad, y esa circunstancia no contribuye al perfeccionamiento de una política adecuada al logro de los fines perseguidos por la norma, puede prescindir de ella luego de la ponderación que haga de la realidad que pretende controlar. [Ver Sentencia C-226/02 M.P. Álvaro Tafur Galvis.] // La Corte también ha sido constante en afirmar que mientras en el cumplimiento de la función legislativa no resulten contrariados los preceptos fundamentales "bien puede el legislador crear o suprimir figuras delictivas, introducir clasificaciones entre ellas, establecer modalidades punitivas, graduar las penas aplicables, fijar la clase y magnitud de éstas con arreglo a criterios de agravación o atenuación de los comportamientos penalizados, todo de acuerdo con la apreciación, análisis y ponderación que efectúe acerca de los fenómenos de la vida social y del mayor o menor daño que ciertos comportamientos puedan estar causando o lleguen a causar en el conglomerado" [Sentencia C-013/1997 M. P. José Gregorio Hernández Galindo.]. En el mismo sentido "puede consagrar regímenes diferenciados para el juzgamiento y tratamiento de delitos y contravenciones, pudiendo, incluso, realizar diferenciaciones dentro de cada uno de estos grupos, en la medida en que unos y otros se fundamenten en criterios de razonabilidad y proporcionalidad que atiendan una valoración objetiva de elementos tales como, la mayor o menor gravedad de la conducta ilícita, la mayor o menor repercusión que la afectación del bien jurídico lesionado tenga en el interés general y en el orden social, entre otros". [Sentencia C-840 de 2000.] 
cuandoquiera que se desconozcan por el Legislador los principios, valores o derechos alli protegidos. ${ }^{20}$

En efecto, la jurisprudencia de esta Corte ha determinado con claridad que el control constitucional abstracto se ha de efectuar no solamente con referencia a lo dispuesto en el texto literal de la Constitución Política, sino también a una serie de normas y principios que, aunque no están consagrados expresamente en la Carta, representan parámetros de constitucionalidad de obligatoria consideración, en la medida en que la propia Constitución les otorga especial fuerza jurídica por medio de las cláusulas de recepción consagradas en los artículos 93, 94, 44 y 53-. (...)

Según se precisó con claridad en la sentencia C-067 de 2003 (M.P. Marco Gerardo Monroy Cabra), "[e]l hecho de que las normas que integran el bloque de constitucionalidad tengan jerarquía constitucional hace de ellas verdaderas fuentes de derecho, lo que significa que los jueces en sus providencias y los sujetos de derecho en sus comportamientos oficiales o privados deben atenerse a sus prescripciones. Así como el preámbulo, los principios, valores y reglas constitucionales son obligatorios y de forzoso cumplimiento en el orden interno, las normas del bloque de constitucionalidad son fuente de derecho obligatoria para todos los asociados. $(. . .)^{21}$ la condición de ocupar con ellos el máximo peldaño en la escala normativa obliga a que toda la legislación interna acondicione su contenido y ajuste sus preceptos a los estatutos por aquellas adoptados, pues éstos irradian su potestad sobre todo el ordenamiento normativo."

Las normas que forman parte del bloque de constitucionalidad cumplen diversas funciones dentro del ordenamiento jurídico colombiano; en relación con el establecimiento de límites al margen de configuración del Legislador en materia penal, el bloque de constitucionalidad cumple dos funciones distintas: una función interpretativa -sirve de parámetro guía en la interpretación del contenido de las cláusulas constitucionales y en la identificación de las limitaciones admisibles a

20 Se afirmó en este sentido en la sentencia C-148 de 2005: "En ese orden de ideas la Corte ha explicado que si bien el Legislador cuenta con una amplia potestad de configuración normativa para el diseño de la política criminal del Estado y, en consecuencia, para la tipificación de conductas punibles es evidente que no por ello se encuentra vedada la intervención de la Corte cuando se dicten normas que sacrifiquen los valores superiores del ordenamiento jurídico, los principios constitucionales, los derechos fundamentales y como pasa a examinarse las normas internacionales en materia de derechos humanos ratificados por Colombia y que hacen parte del bloque de constitucionalidad (art. 93 C.P.)." En igual sentido, en esta sentencia se precisó que, de conformidad con la jurisprudencia de esta Corte, el control de constitucionalidad se debe realizar "no sólo frente al texto formal de la Carta, sino también frente a otras disposiciones a las que se atribuye jerarquía constitucional -bloque de constitucionalidad estricto sensu-, y en relación con otras normas que aunque no tienen rango constitucional, configuran parámetros necesarios para el análisis de las disposiciones sometidas a su control -bloque de constitucionalidad lato sensu-."

21 Cfr. Sentencia C-531/93. 
los derechos fundamentales-, y una función integradora -provisión de parámetros específicos de constitucionalidad en ausencia de disposiciones constitucionales expresas, por remisión directa de los artículos 93, 94, 44 y 53 Superiores-.

Lo anterior es reitardo en la sentencia C-1076 de 2002 (M.P. Clara Inés Vargas Hernández), en la cual sostuvo la Corte:
“(...) aunque el legislador goza de un amplio margen de discrecionalidad al momento de decidir cuáles conductas merecen juicio de reprochabilidad jurídica, dicha autonomía se encuentra restringida por las pautas que imponen la proporcionalidad y la vigencia de los principios de convivencia pacifica y el orden justo. A esto habría que agregar que el legislador está obligado a mantener las garantías mínimas que se ha comprometido proteger en el ámbito internacional en torno a la protección de los derechos de los asociados. "22

El artículo 93 de la Carta establece la prevalencia en el orden interno de ciertos contenidos de los tratados de derechos humanos ratificados por Colombia. La Corte Constittucional ha precisado que "para que opere la prevalencia de tales tratados en el orden interno, 'es necesario que se den los dos supuestos a la vez, de una parte, el reconocimiento de un derecho humanos, y de la otra que sea de aquellos cuya limitación se prohiba durante los estados de excepción'." 23

La Convención sobre la Esclavitud de 1926 y la Convención Suplementaria de 1956, aún cuando no han sido ratificadas por Colombia, contemplan prohibiciones cuya limitación se prohibe durante los estados de excepción. Como se indicó, la prohibición de la esclavitud consagrada en dichos tratados, tiene el rango de norma de jus cogens (Corte Constitucional, Sentencia C-291 de 2007) y ello implica que su cumplimiento es imperativo para todos los Estados, independientemente de su ratificación convencional.

Adicionalmente, aún cuando en principio no consagran un derecho, las convenciones sobre la esclavitud constituyen fuente de los mismos al prohibir una conducta claramente atentatoria contra la libertad, la autonomía personal y la dignidad.

De esta manera, puede afirmarse que estas convenciones integran el bloque de constitucionalidad que, como se verá, constituye un límite a la discrecionalidad del legislador al momento de crear los delitos y estipular sus elementos constitutivos.

22 Corte Constitucional, sentencia del 12 de marzo de 2002, C-181/02, Demanda de inconstitucionalidad contra los artículos $9^{\circ}$ (total), 20, 25, 27, 29, 30, 44 (parciales), 65 (total), 116, 131, 146, 151 у 157 (parciales) de la Ley 200 de 1995. Actor: Carlos Mario Isaza Serrano. M.P. Marco Gerardo Monroy Cabra.

23 Corte Constitucional, Sentencias C-225/95 y T-568/99. 
Existen en la jurisprudencia constitucional, varios ejemplos en este sentido ${ }^{24}$. En Sentencia C-580/02, la Corte sostuvo que:

“(...) la Conveción contra la Desaparición Forzada de Personas "tiene por objeto fijar pautas a las cuales deben sujetarse los ordenamientos internos de los Estados que hacen parte del sistema interamericano de protección de los derechos humanos en lo que se refiere a la desaparición forzada. En tal medida, sus disposiciones no resultan directamente aplicables en los ordenamientos internos, sino que deben ser desarrolladas por los Estados a través de normas internas. Las cláusulas del tratado imponen a los Estados obligaciones de prevenir, suprimir y sancionar la desaparición forzada, con el fin de erradicarla de los países del sistema interamericano, contribuyendo de este modo a proteger los múltiples derechos fundamentales vulnerados con tal conducta.

Por otra parte, vale la pena resaltar que la Convención, si bien no pretende propiamente definir o regular el contenido y alcance de tales derechos, si impone ciertos deberes a los Estados, como sujetos obligados a protegerlos. Por otra parte, la misma Convención afirma que los Estados no pueden eximirse de cumplir tales deberes en ningún caso, y que el delito no es aceptable ni siquiera durante los estados de excepción. (...)"

En relación con la definición contenida en dicha Convención acerca de esta práctica, determinó la Corte que ella "no pretende determinar directamente los elementos constitutivos de responsabilidad penal individual, ${ }^{25}$ sino que fija ciertos elementos a los cuales las partes deben adecuar su derecho penal interno (...). De tal modo, la definición impone apenas un mínimo de elementos del tipo, pero no afecta la facultad del Estado de asumir mayores responsabilidades en la protección -interna o internacional- de los derechos que se pretenden garantizar a través de la desaparición forzada."

En relación con la naturaleza de esta Convención, afirma la Corte:

24 En sentencia C-291/07 se afirma que tanto la función interpretativa como la función integradora del bloque de constitucionalidad han sido aplicadas por la Corte Constitucional en su jurisprudencia sobre los límites del margen de configuración del legislador en materia penal, sea para identificar un desconocimiento de la Constitución con la ayuda interpretativa de las normas incluidas en el bloque, o para aplicar directamente los parámetros establecidos por tales normas en ausencia de una cláusula constitucional específica.

25 Como ejemplos de tales instrumentos se pueden citar las Resoluciones 808 y 827 de 1993, y el informe de la Comisión de Expertos S/25274, para la creación del Tribunal Penal Internacional para la Antigua Yugoslavia, así como la Resolución 955/94 y su anexo contentivo del Estatuto del tribunal para Ruanda; así como el Estatuto de Roma y el texto final del documento preparatorio de los elementos de los crímenes de los que conoce la Corte Penal Internacional PCNICC/INF/3/Add. 2. 
"A pesar de que la presente Convención no constituye en estricto sentido un tratado de derechos humanos sino más bien un mecanismo de erradicación del delito, comparte con aquellos el mismo fin protector de los derechos esenciales de las personas. ${ }^{26}$ En tal medida, puede afirmarse que desde un punto de vista teleológico la Convención reconoce los derechos humanos y establece mecanismos que contribuyen en gran medida a su protección."

$\mathrm{Y}$ en atención a lo anterior dispone:

"Por lo tanto, de conformidad con el artículo 93 de la Carta, ${ }^{27}$ en concordancia con el artículo 94,28 aquellas garantías adicionales de la Convención, que no estén expresas en la Carta Política o adscritas directamente a

26 Este mismo criterio teleológico ha sido empleado por la Corte en las Sentencias C-574/92 aparte B.1.c); C-179/94, C-225/95 fundamentos 7 y 11, para considerar los tratados de Derecho Internacional Humanitario como parte del corpus de derechos humanos. En el fundamento 7, esta última Sentencia afirma que “(...) estos convenios hacen parte, en sentido genérico, del corpus normativo de los derechos humanos, puesto que, tanto los tratados de derechos humanos en sentido estricto como los convenios de derecho humanitario son normas de ius cogens que buscan, ante todo, proteger la dignidad de la persona humana. Son pues normatividades complementarias que, bajo la idea común de la protección de principios de humanidad, hacen parte de un mismo género: el régimen internacional de protección de los derechos de la persona humana. La diferencia es entonces de aplicabilidad, puesto que los unos están diseñados, en lo esencial, para situaciones de paz, mientras que los otros operan en situaciones de conflicto armado, pero ambos cuerpos normativos están concebidos para proteger los derechos humanos". El carácter determinante de la finalidad protectora de los derechos humanos fundamentales como criterio para integrar al bloque de constitucionalidad quedó al parecer definido en la Sentencia C-179/94 que afirmó: "Finalmente cabe agregar que las disposiciones del derecho internacional humanitario que tratan sobre el manejo de las personas y las cosas vinculadas a la guerra, como las que señalan la forma de conducir las acciones bélicas, se han establecido con el fin de proteger la dignidad de la persona humana y para eliminar la barbarie en los conflictos armados." (resaltado fuera de texto). Ver también Sentencia C-156/99. Reiterando dicho criterio ver: C-423/95, C-578/95, C-092/96 C-135/96, C-040/97 y C-156/99 aparte 2.2.2, SU-256/99.

27 En cuanto establece que "los tratados y convenios internacionales ratificados por el Congreso y que reconocen los derechos humanos y que prohíben su limitación en los estados de excepción, prevalecen en el orden interno"

28 Según este artículo "[1]a enunciación de los derechos y garantías contenidos en la Constitución y en los convenios internacionales vigentes, no debe entenderse como negación de otros que, siendo inherentes a la persona humana, no figuren expresamente en ellos". 
ella, hacen parte del bloque de constitucionalidad ${ }^{29}$ latu sensu. ${ }^{30}$ Es decir, constituyen parámetros para la interpretación de los alcances del artículo 12 constitucional. ${ }^{31}$ "

En idéntico sentido, en sentencia C-177 de 2001 (M.P. Fabio Morón Díaz) sostuvo la Corte Constitucional:

“(...) el tipo penal sobre genocidio que consagró el artículo $322^{a}$. de la Ley 589 del 2000, debe ser interpretado a la luz de los Pactos y Convenios Internacionales sobre Derechos Humanos ratificados por Colombia, de conformidad con el artículo 93 de la Constitución y de acuerdo con los principios y preceptos del Derecho Internacional Humanitario y del Derecho Internacional de los Derechos Humanos que forman parte del "ius cogens."

Por otra parte, en la sentencia C-148 de 2005 (M.P. Álvaro Tafur Galvis), la Corte dio aplicación a la función integradora del bloque de constitucionalidad, al resolver sobre la demanda de inconstitucionalidad interpuesta contra la expresión grave incluida en los tipos penales de genocidio, tortura y tortura en persona protegida ${ }^{32}$ :

29 En la Sentencia C-295/93 la Corte estableció que para que una disposición de un tratado internacional haga parte del bloque de constitucionalidad: “... es necesario que se den los dos supuestos a la vez, de una parte, el reconocimiento de un derecho humano, y de la otra que sea de aquellos cuya limitación se prohiba durante los estados de excepción." Ver también Sentencias C-295/93 y C-092/96 fundamento 11. El hecho de que el artículo 93 se refiera a tratados y no a los derechos en sí mismos y que, por consiguiente para que estos prevalezcan en el ordenamiento interno sería necesario, en principio, que el tratado estableciera expresamente la prohibición de limitarlos en estados de excepción quedó zanjada definitivamente con la incorporación del derecho internacional humanitario al bloque de constitucionalidad, pues no todos los tratados de DIH proscriben la limitación de los derechos consagrados en ellos durante estados de excepción. Algunos ni siquiera consagran propiamente derechos. Sin embargo la Corte afirmó esta circunstancia se deriva de su mismo ámbito de aplicación. Ver Sentencia C-225/95 fundamento 11.

30 La Corte ha dicho que “... conforme a esta acepción, el bloque de constitucionalidad estaría conformado no sólo por el articulado de la constitución sino, entre otros, por los tratados internacionales de que trata el artículo 93 de la Carta, por las leyes orgánicas y, en algunas ocasiones, por las leyes estatutarias ..." Sentencia C-359/97. Posteriormente ha sostenido que las disposiciones que hacen parte del bloque de constitucionalidad latu sensu constituyen “... parámetros para determinar el valor constitucional de las disposiciones sometidas a control" Sentencia C-774/01.

31 En relación con el bloque de constitucionalidad, la Corte ha señalado que no todas las disposiciones de un tratado de derechos humanos entran a ser parte del bloque de constitucionalidad. Al respecto ha dicho: "Si bien es cierto que los tratados internacionales vigentes en Colombia encuentran un incuestionable fundamento en normas constitucionales, ello no significa que todas sus normas integran el bloque de constitucionalidad y sirven de fundamento para realizar el control de constitucionalidad de las leyes que lleva a cabo esta Corporación." (resaltado fuera de texto) Sentencia C-327/97.

32 Demanda de inconstitucionalidad contra las expresiones "grave" contenida en el numeral $1^{\circ}$ del artículo 101 [genocidio] y "graves" contenida en los artículos 137 y 178 [tortura en persona protegida y tortura] de la Ley 599 de 2000 "por la cual se expide el Código Penal" 
“(..) se argumentaba que la inclusión del calificativo "grave" en dichos tipos penales desconocía, entre otras, el bloque de constitucionalidad, que no restringe la configuración de los delitos de tortura o genocidio a las hipótesis de lesiones graves. Dado que la Constitución Política no contiene disposiciones detalladas, ni definiciones, de los delitos de genocidio o tortura, para resolver los cargos formulados contra ambos tipos penales la Corte recurrió a las definiciones consagradas en tratados internacionales de derechos humanos que forman parte del bloque de constitucionalidad, para efectos de determinar si el Legislador había desconocido los límites por ellas impuestos a su margen de configuración en materia penal."

En esta misma sentencia, la Corte recordó que "en Colombia es aplicable la cláusula de favorabilidad en la interpretación de los derechos humanos (contenida entre otras en el art. 4 del Protocolo de San Salvador) -de forma tal que "cuando las normas constitucionales y legales colombianas ofrezcan una mayor protección al derecho fundamental de que se trate éstas habrán de primar sobre el texto de los tratados internacionales, de la misma manera que siempre habrá de preferirse en la interpretación de los mismos la hermenéutica que resulte menos restrictiva para la aplicación del derecho fundamental comprometido”.

En igual medida, en la sentencia C-578 de 2002 (M.P. Manuel José Cepeda Espinosa), la Corte recurrió a la función interpretativa del bloque de constitucionalidad para identificar los límites que debe respetar el legislador penal colombiano, señalando que "en virtud de las obligaciones internacionales del Estado colombiano, el ejercicio de la potestad legislativa de fijar las sanciones y los procedimientos de investigación y juicio de delitos tales como el genocidio, los crímenes de lesa humanidad o los crímenes de guerra, debe efectuarse en forma consistente con el derecho internacional de los derechos humanos y el derecho internacional humanitario, cuyo estándar de protección fue recogido por el Estatuto de Roma de la Corte Penal Internacional ${ }^{33}$."

33 Dijo la Corte: “(...) el ejercicio de las competencias soberanas de los Estados para definir las sanciones y procedimientos penales de graves violaciones a los derechos humanos tales como el genocidio, los crímenes de lesa humanidad o los crímenes de guerra, deberá hacerse de tal forma que resulte compatible con el derecho internacional de los derechos humanos, el derecho internacional humanitario y con los fines de lucha contra la impunidad que resalta el Estatuto de Roma. (...) si bien es cierto que los Estados son soberanos para definir las sanciones y procedimientos penales internos que resulten más adecuados para impedir la impunidad frente a crímenes tales como el genocidio, los crímenes de lesa humanidad o los crímenes de guerra, existe un consenso internacional en torno a que tal regulación debe hacerse de manera compatible con el deber de protección de los derechos humanos y de respeto al derecho internacional humanitario y, por lo tanto, las limitaciones a la soberanía en estas materias han sido aceptadas por los Estados como parte de su compromiso de garantizar la efectividad de tales derechos. El Estatuto de Roma reitera ese compromiso y reafirma el consenso internacional en la materia. El estándar de protección que recoge el Estatuto de Roma no es distinto de otros compromisos internacionales en la materia, pero si más efectivo, por cuanto recoge un anhelo de la comunidad internacional de garantizar que no exista impunidad frente a los crímenes más atroces." 
Por su parte, la Sala Penal de la Corte Suprema de Justicia ha reiterado la obligación de las autoridades colombianas de integrar el bloque de constitucionalidad al ejercicio de sus funciones, particularmente en materia de investigación y juzgamiento en Justicia y Paz:

"La dinámica procesal consagrada en la Ley de Justicia y Paz reclama de los funcionarios judiciales la plena observancia de normas constitucionales y de instrumentos internacionales (...).

De acuerdo con lo dispuesto en el artículo 29 de la Constitución Política nadie podrá ser juzgado sino conforme a leyes preexistentes al acto que se le imputa, ante juez o tribunal competente y con observancia de la plenitud de las formas propias de cada juicio.

Esa consagración constitucional del principio de legalidad de los delitos $y$ de las penas, reconocido desde la época de la Revolución Francesa, protege y garantiza la libertad y la igualdad de las personas contra posibles arbitrariedades de los jueces. Dicho postulado exige que quienes vayan a ser objeto de una sanción penal conozcan con anticipación las conductas que son reprochables por el legislador y las sanciones que habrán de imponerse.

La reserva legal, como expresión de la soberanía popular y del principio democrático, asegura que sea el Congreso de la República el que defina las conductas punibles y sus sanciones ex post facto, es decir, establecidas con posterioridad a la realización de los hechos.

(...)

La obligatoriedad de las normas humanitarias y su integración en el bloque de constitucionalidad imponen al Estado-todo-adaptar las normas internas a los contenidos del derecho internacional humanitario.

En este orden de ideas, las autoridades colombianas deben observar no solo la normatividad interna sino aquella integrada en el bloque de constitucionalidad $y$ las decisiones proferidas por organismos internacionales, tales como el Comité de Derechos Humanos y la Corte Interamericana de Derechos Humanos.

Bajo esos parámetros, la labor de la fiscalía, no solo en la etapa de investigación y verificación sino de adecuación típica de la conducta, así como la de los jueces que de alguna manera intervienen en los procesos de justicia y paz, debe estar orientada por esos principios y mandatos superiores. ${ }^{34}$

Por otra parte, en relación con la validez del Estatuto de la Corte Penal Internacional como fuente de interpretación, la Corte Constitucional, en la sentencia que revisó la constitucionalidad de dicho instrumento, sostuvo que:

34 Corte Suprema de Justicia, Sala Penal. Proceso No. 31.539, Auto del 31 de Julio de 2009. M.P. Augusto Ibáñez Guzmán. 
"Las normas del Estatuto surten efectos dentro del ámbito de la competencia de la Corte Penal Internacional. Las disposiciones en él contenidas no remplazan ni modifican las leyes nacionales de tal manera que a quien delinca en el territorio nacional se le aplicará el ordenamiento jurídico interno y las autoridades judiciales competentes al efecto son las que integran la administración de justicia colombiana." ${ }^{, 35}$

De acuerdo con lo anterior, el Estatuto de Roma de ninguna manera puede, por ejemplo, incorporar nuevos tipos penales al ordenamiento interno colombiano. Sin embargo, ello no impide que aquella normatividad pueda ser utilizada para interpretar los tipos penales ya existentes. En primer lugar, porque "las conductas punibles de competencia de la Corte Penal Internacional comprenden las violaciones a los parámetros fundamentales de respeto por el ser humano que no pueden ser desconocidos, ni aún en situaciones de conflicto armado internacional o interno, los cuales han sido gradualmente identificad os y definidos por la comunidad internacional a lo largo de varios siglos con el fin de superar la barbarie" 36 . Además, ha sostenido la Corte Constitucional que:

"Los fines enunciados en el Preámbulo del tratado desarrollan principios de la Carta, como quiera que la efectividad de "los principios, derechos y deberes consagrados en la Constitución”, se satisface cuando se desarrollan instrumentos eficaces para la lucha contra la impunidad, se garantiza el acceso a la justicia y se "asegura la convivencia pacifica y la vigencia de un orden justo" (artículo 2, CP). Los fines que orientarán el ejercicio de las funciones de la Corte Penal Internacional, reafirman la inviolabilidad del derecho a la vida (artículo 11, CP), garantizan la igualdad de las personas (artículo 13) y confirman el rechazo a la tortura, a la desaparición forzada (artículo 12, CP), a la esclavitud, a la servidumbre y a la trata de seres humanos en todas sus formas (artículo 17). Encuentra esta Corte, por lo tanto, que el Estatuto de Roma está inspirado en valores que no difieren de aquellos que orientan nuestro ordenamiento constitucional, y representa una cristalización del consenso internacional en torno al deber de protección de los seres humanos como un compromiso compartido por la comunidad de Estados. ${ }^{, 37}$

En relación con la validez de los Elementos de Crímenes de la Corte Penal Internacional ${ }^{38}$ debe anotarse que los mismos fueron creados en virtud del artículo 9

35 Corte Constitucional, Sentencia C-578 de 2002. M.P. Manuel José Cepeda Espinosa.

36 Ibíd.

37 Ibid.

38 Las Reglas de Procedimiento y Prueba y los Elementos de los Crímenes de la Corte Penal Internacional, aprobados por la Asamblea de los Estados Parte de la Corte Penal Internacional (Nueva York, Septiembre de 2002), fueron aprobadas mediante la Ley 1268 del 31 de Diciembre de 2010 y su constitucionalidad fue declarada mediante sentencia C-801 de 2009, M.P. Gabriel Eduardo Mendoza Martelo. 
del Estatuto, para precisar la estructura de cada conducta catalogada como crimen en dicho instrumento y delimitar su interpretación. Colombia participó en la Comisión Preparatoria, presentando más de cincuenta documentos con comentarios y propuestas ${ }^{39}$ y expresando su posición a partir de criterios relativos a la conveniencia y a la conformidad con el derecho constiotucional colombiano, entre otros.

Adicionalmente, mediante sentencia C-801 de 2009, se declaró su constitucionalidad, advirtiendo que "el Estatuto de Roma y los instrumentos que lo complementan no modifican el derecho interno que aplican las autoridades jurisdiccionales colombianas en ejercicio de las competencias que le son propias dentro del territorio de la República".

No obstante, en relación con la validez del Estatuto de la Corte Penal Internacional como criterio de interpretación de la legislación interna, expuso la Corte Suprema de Justicia:

“(...) al lado de la importancia que tiene la adopción en la legislación interna de los tipos penales encaminados a prevenir las violaciones graves al derecho internacional humanitario, debe señalarse que el Estatuto de Roma entró a reforzar la eficacia de la persecución y sanción de los crímenes de guerra a nivel nacional mediante la creación de un órgano jurisdiccional de carácter permanente que complementa a las jurisdicciones nacionales y las incentiva a ejercer su jurisdicción sobre los tipos penales recogidos en el artículo $8^{\circ}$ del Estatuto en cuestión ${ }^{40}$.

(...) cabe citar que el Estatuto de Roma, como ya se anotó, se constituye en parámetro básico de la sistematización y positivización de los delitos de lesa humanidad.

(...)

Pero es claro para la Corte que la no incorporación en la legislación interna de una norma que en estricto sentido defina los delitos de lesa humanidad, no impide su reconocimiento a nivel nacional, porque con base en el principio de integración-artículo 93 de la Carta Política-debe acudirse a los instrumentos internacionales que por virtud del bloque de constitucionalidad obligan en la interpretación y aplicación de las normas.

(...)

Por lo tanto, para efectos de calificar los crimenes atroces cometidos contra la población civil por los grupos armados al margen de la ley, dentro del contexto de los llamados crimenes de lesa humanidad, debido a que se trata de una variedad de delitos de graves violaciones a los derechos humanos, que fueron tipificados en la legislación nacional bajo títulos que consagran bienes jurídicos tradicionales, los operadores jurídicos deberán remitirse al

39 Así lo constató la Corte Constitucional en la sentencia C-578 de 2002.

40 Ensayos sobre la Corte Penal Internacional. Héctor Olásolo Alonso. Bogotá. Pontificia Universidad Javeriana, Medellín, Biblioteca Jurídica Dike, 2009, pag. 487. 
Estatuto de la Corte Penal Internacional para fijar su contexto, en concreto, a su artículo $7^{\circ}$, concordándolo con las normas del Código Penal nacional que castigan tales comportamientos." ${ }^{\prime 1}$

Lo anterior constituye un claro ejemplo en que puede recurrirse al Estatuto a fin de interpretar de manera más garantista la legislación penal colombiana.

Lo propio realizó la Corte Constitucional, en la sentencia T-453 de 2005 (M.P. Manuel José Cepeda Espinosa), en la cual, aún cuando los hechos del caso no ocurrieron en un contexto de conflicto armado, la Sala acudió a las normas del Estaturo de Roma y a las Reglas de Procedimiento y Prueba de la Corte Penal Internacional, en la medida en que las mismas ilustraban la trascendencia del tema tratado (protección a víctimas de violencia sexual dentro del proceso penal).

\section{Análisis del tipo penal de esclavitud sexual o prostitución forzada}

Al igual que en las demás conductas penalizadas en el Título II del Libro $2^{\circ}$ del Código Penal, para determinar el contenido del tipo penal de esclavitud sexual es necesario acudir a otras fuentes normativas.

A continuación, se estudiará cada uno de los elementos típicos, recurriendo a la legislación penal colombiana y la jurisprudencia de las altas cortes, así como a la normativa internacional que ha sido incorporada al ámbito interno a través del bloque de constitucionalidad y los pronunciamientos de algunos órganos internacionales, cuya validez como fuentes de interpretación ha sido examinada en el acápite anterior.

\section{a. El sujeto activo}

El sujeto activo de los delitos contra personas y bienes protegidos por el derecho internacional humanitario y, en particular, el del tipo penal de esclavitud sexual, es indeterminado, en tanto de la descripción típica - "el que"- no se deriva ninguna característica que lo califique.

No obstante, no puede perderse de vista que la obligación de respetar el derecho internacional humanitario le compete a las partes en conflicto armado, es decir, a las fuerzas del Estado o a los grupos armados no estatales en confrontación y, particularmente, a quienes participan directamente en las hostilidades. En este sentido, son ellos los llamados a infringir la normativa humanitaria $\mathrm{y}$, por ende, a incurrir en las conductas tipificadas en el Título II del Libro $2^{\circ}$ del Código Penal, aún cuando el Estado no haya reconocido su estatus de combatiente ${ }^{42}$.

41 Corte Suprema de Justicia, Proceso No. 32022, Auto del 21 de septiembre de 2009, M.P. Sigifredo Espinosa Pérez.

42 Valencia Villa, Alejandro. Derecho Internacional Humanitario. Conceptos básicos. Infracciones en el conflicto armado colombiano. 2007. p. 136. 
Según Alejandro Valencia Villa, se entiende por participación directa en las hostilidades "los actos de guerra que por su naturaleza o propósito, estén destinados a causar daños concretos al material o al personal de las fuerzas armadas adversas." 43

\section{b. El uso de la fuerza}

Desde sus diversas acepciones gramaticales ${ }^{44}$, la fuerza puede entenderse como el ejercicio de la violencia o la aplicación del poder físico o moral para obligar a alguien a que haga algo.

A partir de esta definición, puede afirmarse que la fuerza a la que se refiere el tipo penal de esclavitud sexual, es equivalente a la violencia exigida para la configuración de otros delitos sexuales como el acceso carnal violento y el acto sexual violento (Código Penal, artículos 205 y 206).

La violencia, en tanto ingrediente normativo de los delitos sexuales, puede definirse como el medio utilizado para inhibir la autodeterminación sexual como facultad de la persona de disponer de su propia sexualidad ${ }^{45}$. Asimismo, la ha definido la Corte Suprema de Justicia, como "la fuerza, el constreñimiento, la presión física o psíquica -intimidación o amenaza- que el agente despliega sobre la víctima para hacer desaparecer o reducir sus posibilidades de oposición o resistencia a la agresión que ejecuta"46.

La Sala de Casación Penal se ha referido en reiterada jurisprudencia a este elemento normativo, precisando que en conductas como la de acceso carnal violento, la violencia ejercida por el autor puede ser de índole física o moral ${ }^{47}$ (e incluso puede presentarse una combinación entre estas ${ }^{48}$ ).

De acuerdo con dicha instancia, la violencia física

“(...) se presenta si durante la ejecución del injusto el sujeto activo se vale de cualquier vía de hecho o agresión contra la libertad física o la libertad de disposición del sujeto pasivo o de terceros, que dependiendo las circunstancias de cada situación en particular resulte suficiente a fin de vencer la resistencia

43 Ibid.

44 Tomadas (no de manera textual) del Diccionario de la Lengua Española, vigésima segunda edición, consultado el 10 de marzo de 2010, a través del sitio web de la Real Academia Española http://www. rae.es/rae.html.

45 Corte Suprema de Justicia, Sala de Casación Penal. Proceso No. 25.578, sentencia del 08 de octubre de 2008. M.P. Julio Enrique Socha Salamanca.

46 Corte Suprema de Justicia, Sala de Casación Penal. Proceso No. 25.743, sentencia del 26 de octubre de 2006. M.P. Álvaro Orlando Pérez Pinzón.

47 Corte Suprema de Justicia, Sala de Casación Penal. Proceso No. 23.508, sentencia del 23 de septiembre de 2009. M.P. Julio Enrique Socha Salamanca.

48 Corte Suprema de Justicia, Sala de Casación Penal. Proceso No. 20.413, sentencia del 23 de enero de 2008. M.P. Julio Enrique Socha Salamanca. 
que una persona en idénticas condiciones a las de la víctima pudiera ofrecer al comportamiento desplegado.

\section{(...)}

"La violencia moral, en cambio, consiste en todos aquellos actos de intimidación, amenaza o constreñimiento tendientes a obtener el resultado típico, que no implican el despliegue de fuerza física en los términos considerados en precedencia, pero que tienen la capacidad de influir de tal manera en la víctima para que ésta acceda a las exigencias del sujeto agente, a cambio de que no le lesione grave y seriamente la vida, integridad personal, libertad o cualquier otro derecho fundamental propio o de sus allegados" $\$ 9$

En relación con el elemento normativo de la fuerza, el Tribunal Penal Internacional para Ruanda sostuvo, que bajo ciertos contextos, la coerción no debe necesariamente manifestarse mediante una demostración de fuerza física:

“(...) Las amenazas, la intimidación, el chantaje y otras formas de violencia que sacan provecho del miedo o el desasosiego pueden caracterizar la coerción, la cual puede ser inherente a ciertas circunstancias, por ejemplo un conflicto armado (...)" ${ }^{\text {"50 }}$.

Resulta importante precisar que la violencia exigida para confirgurar el delito " $n o$ es la que se emplea en la realización del comportamiento sexual reprochado sino la utilizada para doblegar la voluntad de la víctima (...)" ${ }^{51}$, para vencer su resistencia ${ }^{52}$; “(...) su ocurrencia ni siquiera tiene que ser concomitante a la perpetración de la acción que configura el acceso, siempre y cuando la violencia objetivamente valorada ex ante sea la que determine su realización"

De esta manera, resalta la Corte, lo que debe verificarse es que los actos de violencia desplegados por el autor de la conducta fueron idóneos para someter la voluntad de la víctima ${ }^{54}$, dicho de otra manera, que existió un nexo de causalidad entre la fuerza y el acto sexual, de forma tal que pueda afirmarse que este último se ha producido como consecuencia del uso de la primera ${ }^{55}$.

49 Ibid.

50 Tribunal Penal Internacional para Ruanda, Prosecutor vs Jean Paul Akayesu. Sentencia del 02 de septiembre de 1998, párr. 688. Citado en Corporación Humanas. Guía para llevar casos de violencia sexual. Propuestas de argumentación para enjuiciar crímenes de violencia sexual cometidos en el marco del conflicto armado colombiano, pág. 91.

51 Sentencia del 26 de octubre de 2006, radicación 25.743 y en el mismo sentido, sentencia del 17 de septiembre de 2008, radicación 21.691 (citadas en Corte Suprema de Justicia, Sala de Casación Penal, Proceso No. 23.508, sentencia del 23 de septiembre de 2009).

52 Ibid.

53 Sentencia del 23 de enero de 2008, radicación 20.413, citada supra.

54 Ibid.

55 Corte Suprema de Justicia, Sala de Casación Penal. Proceso No. 25.743, sentencia del 26 de octubre de 2006. M.P. Álvaro Orlando Pérez Pinzón. 
El uso de la fuerza o la coacción, o la amenaza de su empleo, conllevan en sí mismos la anulación del consentimiento o voluntad de la víctima de participar en el acto sexual. En este sentido, el Tribunal Penal para la Antigua Yugoslavia (TPIY) afirmó que:

"463. (...) Si la víctima fue objeto de presiones físicas o psicológicas, o controlada mediante la fuerza, etc., para la comisión de la violencia sexual o de violación, no es posible considerar que esta haya prestado su consentimiento, ya que se elimina toda su capacidad volitiva para consentir el acto sexual. (...)

464. (...) No puede haber verdadero consentimiento cuando la víctima "está sometida a actos de violencia o si ha sido forzada, detenida o sometida a presiones psicológicas o si temía sufrirlas o fue amenazada de tales actos", o cuando la víctima "consideró razonablemente que, si no se sometía, otra persona podría sufrir tales actos, ser amenazada o forzada por el miedo"

En relación con lo anterior, debe advertirse que el elemento normativo del uso de la fuerza no se desvirtúa ante la ausencia de gritos o actos de resistencia física de la víctima (en la medida en que el sometimiento de su voluntad puede incluir el control de cualquier reacción por parte de ésta) $)^{57}$. En este sentido, la Sala Penal de la Corte Suprema de Justicia acogió lo dispuesto en las Reglas de Procedimiento y Prueba de la Corte Penal Internacional, de acuerdo con las cuales el consentimiento de la víctima no puede inferirse del silencio o de la falta de resistencia, en particular, "cuando la fuerza, la amenaza de la fuerza, la coacción o el aprovechamiento de un entorno coercitivo hayan disminuido su capacidad para dar un consentimiento voluntario y libre" (Regla No. 70, literales a y c) $)^{58}$.

En el mismo sentido, la Corte Constitucional en sentencia T-458 de 2007 concluyó que si bien la falta de consentimiento puede expresarse a través del rechazo, la oposición o la defensa ante los actos de violencia, el hecho de que estos no se presenten no implica, en sí mismo, la voluntad de la víctima en consentir el acto sexual ${ }^{59}$. De esta manera, la Corte ratifica el derecho de las víctimas de delitos sexuales a que se entienda que no existe consentimiento real y libre de presiones, por la simple ausencia de rechazo físico o de expresiones que lo exterioricen ${ }^{60}$.

56 Tribunal Penal Internacional para la Antigua Yugoslavia. Prosecutor vs Dragoljub Kunarac, Radomir Kovac y Zoran Vukovic. Sentencia del 22 de febrero de 2001. Citado en Corporación Humanas, Op. cit., pág. 107.

57 Sentencia del 23 de septiembre de 2009, radicación 23.508, citada supra. Previamente, la Sala Penal de la Corte Suprema de Justicia había sostenido que no puede inferirse consentimiento de la víctima de la ausencia de huellas físicas de la violencia (Sentencia del 08 de mayo de 1996, radicación 9401, M.P. Fernando Arboleda Ripoll).

58 Corte Suprema de Justicia, Sala de Casación Penal. Proceso No. 25.578, sentencia del 08 de octubre de 2008. M.P. Julio Enrique Socha Salamanca.

59 Corporación Humanas. Op. cit., pág. 43.

60 Corte Constitucional, Sentencia T-458 del 07 de junio de 2007, M.P. Álvaro Tafur Galvis. 
Frente a la ausencia de consentimiento, el TPIY verificó que en algunos sistemas jurídicos se considera que determinados actos sexuales constituyen una violación no solo cuando se acompañan del empleo de la fuerza o de la amenaza de la misma, sino también en presencia de otras circunstancias particulares, como cuando la víctima se encuentra en una situación de especial vulnerabilidad o cuando ha sido puesta en incapacidad de resistir ${ }^{61}$. El común denominador a todas estas circunstancias es que permiten o tienen por resultado hacer caso omiso de la voluntad de la víctima o neutralizar de manera temporal o duradera su capacidad de rechazar libremente el acto sexual ${ }^{62}$.

Señala el TPIY que ante ciertos factores, el libre consentimiento o voluntad de la víctima resultan imposibles o irrelevantes; estos factores son i) la amenaza o el uso de la fuerza u otros mecanismos de coerción, ii) el miedo a la violencia, iii) el engaño o las falsas promesas, iv) el abuso de poder, v) la posición de vulnerabilidad de la víctima, vi) circunstancias de detención o cautiverio de la víctima, vii) presión psicológica y viii) ciertas condiciones socio-económicas ${ }^{63}$. En este sentido, vale la pena destacar que la Corte Suprema de Justicia ha señalado, que a fin de valorar la violencia en los delitos sexuales, deben tomarse en consideración factores como la seriedad del ataque, la desproporción de fuerzas y el estado de inferioridad o vulnerabilidad de la persona agredida ${ }^{64}$.

\section{c. Con ocasión y en desarrollo del conflicto armado}

Tal como lo afirma Alejandro Valencia Villa, "si el derecho internacional humanitario se aplica en situaciones de conflicto armado, toda conducta que infrinja este derecho tiene que darse en esta situación" ${ }^{\circ 5}$. De esta manera, todos los tipos penales contenidos en el Título II del Libro $2^{\circ}$ del Código Penal, exigen, para la configuración de la conducta típica, que la misma se dé "con ocasión y en desarrollo del conflicto armado".

Este ingrediente normativo implica probar dos elementos: i) la existencia de un conflicto armado y ii) la relación entre la conducta delictiva y el conflicto.

En relación con el primero de estos elementos, en sentencia C-291 de 2007 sostuvo la Corte Constitucional:

61 Tribunal Penal Internacional para la Antigua Yugoslavia, El Fiscal vs Kunarac y otros, párr. 446. Citado en Corporación Humanas, Op. cit., pág. 105.

62 Ibid, párr. 452.

63 Tribunal Penal Internacional para la Antigua Yugoslavia. Prosecutor vs Dragoljub Kunarac, Radomir Kovac y Zoran Vukovic. Sentencia del 22 de febrero de 2001, párr. 524. Traducción de la autora.

64 Sentencia de 26 de noviembre de 2003, radicación 17.068 (citada en Corte Suprema de Justicia, Sala de Casación Penal, Sentencia del 23 de enero de 2008, radicación 20.413).

65 Alejandro Valencia Villa, Op. cit. 
"La naturaleza voluble de los conflictos armados actuales ${ }^{66}$ ha llevado a la jurisprudencia internacional a definirlos como "el recurso a la fuerza armada entre Estados, o la violencia armada prolongada entre las autoridades gubernamentales y grupos armados organizados, o entre tales grupos, dentro de un Estado"67. En el caso de los conflictos armados internos, el adjetivo "prolongada" 68 busca excluir de esta definición los casos de meros disturbios civiles, revueltas esporádicas o actos terroristas aislados. ${ }^{69}$ Esta definición se refleja en lo dispuesto en el artículo 1 del Protocolo Adicional II sobre su "ámbito de aplicación material", en el cual se dispone:

"1. El presente Protocolo, que desarrolla y completa el artículo 3 Común a los Convenios de Ginebra del 12 de agosto de 1949, sin modificar sus actuales condiciones de aplicación, se aplicará a todos los conflictos armados que no estén cubiertos por el artículo 1 del Protocolo adicional a los Convenios de Ginebra del 12 de agosto de 1949 relativo a la protección de las víctimas de los conflictos armados internacionales (Protocolo I) y que se desarrollen en el territorio de una Alta Parte contratante entre sus fuerzas armadas y fuerzas armadas disidentes o grupos armados organizados que, bajo la dirección de un mando responsable, ejerzan sobre una parte de dicho territorio un control tal que les permita realizar operaciones militares sostenidas y concertadas y aplicar el presente protocolo.

66 Tribunal Penal para la Antigua Yugoslavia, caso del Fiscal vs. Aleksovsky, sentencia del 25 de junio de 1999.

67 Traducción informal: "a resort to armed force between States or protracted armed violence between governmental authorities and organised armed groups or between such groups within a State". Caso del Fiscal v. Dusko Tadic, No. IT-94-1-AR72, decisión de la Sala de Apelaciones sobre su propia jurisdicción, 2 de octubre de 1995, par. 70. Esta regla ha sido reiterada en numerosas decisiones del Tribunal Penal Internacional para la Antigua Yugoslavia, entre las cuales se cuentan los casos de Fiscal vs. Aleksovsky, sentencia del 25 de junio de 1999; Fiscal vs. Blagojevic y Jokic, sentencia del 17 de enero de 2005; Fiscal vs. Tihomir Blaskic, sentencia del 3 de marzo del 2000; Fiscal vs. Radoslav Brdjanin, sentencia del $1^{\circ}$ de septiembre de 2004; Fiscal vs. Anto Furundzija, sentencia del 10 de diciembre de 1998; Fiscal vs. Stanislav Galic, sentencia del 5 de diciembre de 2003; Fiscal vs. Enver Hadzihasanovic y Amir Kubura, sentencia del 15 de marzo de 2006; Fiscal vs. Dario Kordic y Mario Cerkez, sentencia del 26 de febrero de 2001; Fiscal vs. Sefer Halilovic, sentencia del 16 de noviembre de 2005; Fiscal vs. Dragoljub Kunarac y otros, sentencia de la Sala de Apelaciones 12 de junio de 2002; Fiscal vs. Momcilo Krajisnik, sentencia del 27 de septiembre de 2006.

68 El Tribunal Penal para la Antigua Yugoslavia usa el término "protracted”, en la versión inglesa de las sentencias.

69 Tribunal Penal para la Antigua Yugoslavia, casos del Fiscal vs. Dario Kordic y Mario Cerkez, sentencia de la Sala de Apelaciones del 17 de diciembre de 2004; Fiscal vs. Sefer Halilovic, sentencia del 16 de noviembre de 2005; y Fiscal vs. Dragoljub Kunarac y otros, sentencia de la sala de apelaciones del 12 de junio de 2002 . 


\section{El presente protocolo no se aplicará a las situaciones de tensiones internas} $y$ de disturbios interiores, tales como los motines, los actos esporádicos y aislados de violencia y otros actos análogos, que no son conflictos armados."

Para efectos de establecer en casos concretos si un determinado conflicto ha trascendido el umbral de gravedad necesario para ser clasificado como un conflicto armado interno, la jurisprudencia internacional ha recurrido principalmente a dos criterios: (i) la intensidad del conflicto, y (ii) el nivel de organización de las partes. ${ }^{70}$ Al apreciar la intensidad de un determinado conflicto, las Cortes internacionales han aplicado, por ejemplo, factores tales como la seriedad de los ataques y si ha habido un incremento en las confrontaciones armadas ${ }^{71}$, la extensión de las hostilidades a lo largo de un territorio y de un período de tiempo ${ }^{72}$, el aumento en las fuerzas armadas estatales y en su movilización, así como la movilidad y distribución de armas de las

70 El Tribunal Internacional para la Antigua Yugoslavia ha explicado en este sentido: "Bajo este test, al establecer la existencia de un conflicto armado de carácter interno la Sala debe apreciar dos criterios: (i) la intensidad del conflicto y (ii) la organización de las partes [ver sentencia del caso Tadic, par. 562]. Estos criterios se utilizan 'solamente para el propósito, como mínimo, de distinguir un conflicto armado de actos de delincuencia, insurrecciones desorganizadas y de corta duración, o actividades terroristas, que no están sujetas al Derecho Internacional Humanitario' [sentencia del caso Tadic, par. 562]. (...) En consecuencia, un cierto grado de organización de las partes será suficiente para establecer la existencia de un conflicto armado. (...) Esta posición es consistente con otros comentarios autorizados sobre el tema. Un estudio por el CICR sometido como documento de referencia a la Comisión Preparatoria para el establecimiento de los Elementos de los Crímenes para la CPI notó que: 'La determinación de si existe un conflicto armado no internacional no depende del juicio subjetivo de las partes a ese conflicto; debe ser determinado con base en criterios objetivos; el término 'conflicto armado' presupone la existencia de hostilidades entre fuerzas armadas organizadas en mayor o menor medida; debe haber oposición por las fuerzas armadas, y una cierta intensidad de los combates.(...)". [Traducción informal: "Under this test, in establishing the existence of an armed conflict of an internal character the Chamber must assess two criteria: (i) the intensity of the conflict and (ii) the organisation of the parties.[See Tadic Trial Judgement, para 562. JThese criteria are used "solely for the purpose, as a minimum, of distinguishing an armed conflict from banditry, unorganized and short-lived insurrections, or terrorist activities, which are not subject to international humanitarian law." [Tadic Trial Judgement, para 562.] (...) Therefore, some degree of organisation by the parties will suffice to establish the existence of an armed conflict. (...)This position is consistent with other persuasive commentaries on the matter. A study by the ICRC submitted as a reference document to the Preparatory Commission for the establishment of the elements of crimes for the ICC noted that: The ascertainment whether there is a non-international armed conflict does not depend on the subjective judgment of the parties to the conflict; it must be determined on the basis of objective criteria; the term 'armed conflict' presupposes the existence of hostilities between armed forces organised to a greater or lesser extent; there must be the opposition of armed forces and a certain intensity of the fighting.(...)']. Tribunal Internacional para la Antigua Yugoslavia, caso del Fiscal vs. Fatmir Limaj y otros, sentencia del 30 de noviembre de 2005.

71 Ver, entre otros, los casos Fiscal v. Dusko Tadic, No. IT-94-1-AR72, decisión de la Sala de Apelaciones sobre su propia jurisdicción, 2 de octubre de 1995; Fiscal vs. Fatmir Limaj y otros, sentencia del 30 de noviembre de 2005; Fiscal vs. Zejnil Delalic y otros (caso Celebici), sentencia del 16 de noviembre de 1998.

72 Ver, entre otros, los casos Fiscal v. Dusko Tadic, No. IT-94-1-AR72, decisión de la Sala de Apelaciones sobre su propia jurisdicción, 2 de octubre de 1995; Fiscal vs. Fatmir Limaj y otros, sentencia del 30 de noviembre de 2005 
distintas partes enfrentadas ${ }^{73}$. En cuanto a la organización de los grupos enfrentados, las cortes internacionales la han apreciado de conformidad con criterios tales como la existencia de cuarteles, zonas designadas de operación, y la capacidad de procurar, transportar y distribuir armas. ${ }^{74 \text { ", }}$

De aquí pueden establecerse algunos elementos indicativos de la existencia de un conflicto armado no internacional:

i) Una situación de violencia armada prolongada y de cierta intensidad, dentro del territorio de un Estado: tal como lo afirma la Corte, el carácter prolongado de los actos violentos es lo que permite diferenciarlos de otros actos aislados o esporádicos de violencia; en cuanto a la intensidad del conflicto, se pueden observar criterios como la seriedad de los ataques ${ }^{75}$, el incremento en las confrontaciones armadas y la extensión de las hostilidades a lo largo de un territorio y un periodo de tiempo, entre otros.

ii) Que dichos actos de violencia se den entre las fuerzas armadas del Estado y grupos armados organizados, o entre tales grupos;

iii) Que los grupos armados en confrontación posean cierto nivel de organización (esto es, que cuenten con la dirección de un mando responsable, cuarteles, zonas designadas de operación y capacidad para procurar, transportar y distribuir armas, entre otros factores);

iv) Que estos grupos ejerzan control sobre una parte del territorio del Estado, es decir, que sus miembros y estructuras militares tengan cierta permanencia y capacidad de circulación en una determinada zona, en la cual, además, hayan establecido unidades logísticas, sanitarias o militares y desarrollado acciones militares con cierta periodicidad. Otra característica puede ser el ejercicio de un control político sobre parte de la población civil de la zona dominada ${ }^{76}$.

v) Que cuenten con la capacidad de realizar operaciones militares sostenibles y concertadas. ${ }^{77}$

73 Ver, entre otros, los casos Fiscal vs. Fatmir Limaj y otros, sentencia del 30 de noviembre de 2005; Fiscal vs. Zejnil Delalic y otros (caso Celebici), sentencia del 16 de noviembre de 1998.

74 Ver, entre otros, el caso Fiscal vs. Fatmir Limaj y otros, sentencia del 30 de noviembre de 2005.

75 Según el artículo 49 del Protocolo Adicional I, se entiende por "ataques" los actos de violencia contra el adversario, sean ofensivos o defensivos. Algunos ejemplos pueden ser combates, asaltos,emboscadas, hostigamientos (en Valencia Villa, Alejandro, Op. cit.)

76 Tomado de Valencia Villa, Alejandro, Op. cit.

77 El Estatuto de Roma solo exige una situación de violencia prolongada para establecer la existencia de un conflicto armado. En efecto, el artículo 8.2.f del Estatuto determina que los crímenes de guerra en conflictos armados no internacionales son aquellos que "tienen lugar en el territorio de un Estado cuando existe un conflicto armado prolongado entre las autoridades gubernamentales y grupos armados organizados o entre tales grupos", sin exigir que los mismos tengan un mando responsable y ejerzan control territorial. No obstante, la legislación nacional ha acogido lo dispuesto en el artículo $1^{\circ}$ del Protocolo II, definiendo como grupo armado al margen de la ley el grupo de guerrilla o de autodefensas, o una parte significativa e integral de los mismos como bloques, frentes $\mathrm{u}$ otras modalidades de esas mismas organziaciones, que bajo la dirección de un mando responsable, ejerza sobreuna parte del territorio un control tal que le permita realizar operaciones militares sostenidas y concertadas (artículo $1^{\circ}$ de la Ley 975/05 y artículo 3, parágrafo $1^{\circ}$, de la Ley 782/02). 
Siempre que se verifiquen estas condiciones podrá afirmarse que existe un conflicto armado no internacional, en el marco del cual debe aplicarse el derecho internacional humanitario, aún cuando la existencia del mismo no haya sido reconocida a través de un acto político.

No obstante, para efectos de la aplicación de los tipos penales consagrados en el Título II del Libro $2^{\circ}$ del Código Penal, en el marco de los procesos de la Ley 975 de 2005, ha determinado la Corte Suprema de Justicia que dicho acto político se concretó en la expedición misma de la ley de Justicia y Paz, mediante la cual se dio un marco jurídico a la desmovilización de grupos armados al margen de la ley, cuyas acciones no pueden desvincularse del derecho internacional humanitario. En este sentido, sostuvo la Corte:

"No desconoce la sala que el reconocimiento de la existencia de un conflicto
armado es un acto político de complicadas consecuencias, que no corresponde
declarar a la judicatura, pero esa situación no impide que exclusivamente, para
efectos de la aplicación de la ley de justicia y paz, conforme su naturaleza y
fines, el operador judicial, al momento de investigar y juzgar las conductas que
pueden encajar en las descripciones típicas de los "delitos contra personas
y bienes protegidos por el derecho internacional humanitario", verifique
la existencia de esa situación en aras de salvaguardar los valores protegidos
por el derecho internacional humanitario, que están por encima de cualquier
consideración política.
En este sentido, la verificación judicial de que ciertos comportamientos se
encuentran vinculados con el conflicto armado, se halla legitimada en el
contexto de la Ley 975 de 2005 , precisamente porque el acto político ya ha sido
consignado expresamente dentro de los fundamentos de la norma, en particular,
cuando allí se establecen como fines de la misma la consecución de la paz y la
reconciliación nacional, significando de entrada que la desmovilización que
allí se consagra opera respecto de miembros de grupos armados al margen de
la ley, cuyo accionar no podría desvincularse del D.I.H."78

No obstante lo anterior, es preciso establecer frente a cada uno de los actos de dichos grupos, si con ellos se infringió la normativa humanitaria, atendiendo a los criterios temporales, geográficos y materiales de aplicación de la misma. Estos criterios han sido definidos por la Corte Constitucional de la siguiente manera:

"El DIH se aplica automáticamente cuando están dadas las condiciones de índole temporal, espacial y material; tales condiciones hacen que "el ámbito temporal y geográfico tanto de los conflictos armados internos como de los internacionales se extienda más allá del tiempo y lugar exactos de las hostilidades"79; que "una violación de las leyes o costumbres de la guerra

78 Corte Suprema de justicia, Sala de Casación Penal, Auto con radicado No. 32.022, del 21 septiembre de 2009, M.P. Sigifredo Espinosa Pérez.

79 Traducción informal: "the temporal and geographical scope of both internal and international armed conflicts extends beyond the exact time and place of hostilities". Tribunal Penal para la Antigua Yugoslavia, caso del Fiscal v. Dusko Tadic, No. IT-94-1-AR72, decisión de la Sala de Apelaciones sobre su propia jurisdicción, 2 de octubre de 1995. 
[pueda], por lo tanto, ocurrir durante un tiempo y en un lugar en los que no se desarrolla un combate efectivo como tal. (...) el requisito de que los actos del acusado estén relacionados de cerca con el conflicto armado no se incumple cuando los crimenes son remotos, temporal y geográficamente, de los combates como tales"80; y que "las leyes de la guerra [puedan] frecuentemente abarcar actos que, aunque no han sido cometidos en el teatro del conflicto, se encuentran sustancialmente relacionados con éste" ${ }^{81}$

1.2.1. En términos temporales, "el derecho internacional humanitario se aplica desde la iniciación de tales conflictos armados, y se extiende más allá de la cesación de hostilidades hasta que se haya logrado una conclusión general de la paz; o en caso de conflictos internos, cuando se logre un arreglo pacifico"s2.

1.2.2. En términos geográficos, el Derecho Internacional Humanitario se aplica tanto a los lugares en los que materialmente se desarrollan los combates u hostilidades armados, como a la totalidad del territorio controlado por el Estado y los grupos armados enfrentados, así como a otros lugares en donde, si bien no ha habido materialmente una confrontación armada, se han dado hechos que se relacionan de cerca con el conflicto armado. Así lo ha explicado el Tribunal Penal para la Antigua Yugoslavia al precisar que "no existe una correlación necesaria entre el área donde se desarrollan los combates como tales, y el alcance geográfico de las leyes de la guerra". ${ }^{83}$ La jurisprudencia

80 Traducción informal: "A violation of the laws or customs of war may therefore occur at a time when and in a place where no fighting is actually taking place. As indicated by the Trial Chamber, the requirement that the acts of the accused must be closely related to the armed conflict would not be negated if the crimes were temporally and geographically remote from the actual fighting." Tribunal Penal para la Antigua Yugoslavia, caso del Fiscal vs. Dragoljub Kunarac y otros, sentencia de la sala de apelaciones del 12 de junio de 2002.

81 Traducción informal: "The laws of war may frequently encompass acts which, though they are not committed in the theatre of conflict, are substantially related to it." Tribunal Penal para la Antigua Yugoslavia, caso del Fiscal vs. Dragoljub Kunarac y otros, sentencia de la sala de apelaciones del 12 de junio de 2002.

82 Traducción informal: "International humanitarian law applies from the initiation of such armed conflicts and extends beyond the cessation of hostilities until a general conclusion of peace is reached; or, in the case of internal conflicts, a peaceful settlement is achieved". Tribunal Penal para la Antigua Yugoslavia, Caso del Fiscal v. Dusko Tadic, No. IT-94-1-AR72, decisión de la Sala de Apelaciones sobre su propia jurisdicción, 2 de octubre de 1995. Reiterado en los casos de Fiscal vs. Enver Hadzihasanovic y Amir Kubura, sentencia del 15 de marzo de 2006; Fiscal vs. Dario Kordic y Mario Cerkez, sentencia del 26 de febrero de 2001; y Fiscal vs. Momcilo Krajisnik, sentencia del 27 de septiembre de 2006.

83 Traducción informal: "There is no necessary correlation between the area where the actual fighting is taking place and the geographical reach of the laws of war". Tribunal Penal para la Antigua Yugoslavia, caso del Fiscal vs. Dragoljub Kunarac y otros, sentencia de la sala de apelaciones del 12 de junio de 2002. 
internacional ha aceptado que para efectos de aplicar el Derecho Internacional Humanitario "no es necesario establecer la existencia de un conflicto armado dentro de cada municipio implicado. Es suficiente establecer la existencia del conflicto dentro de la región como un todo de la que forman parte dichos municipios"84; que "no es necesario que un determinado municipio sea presa de la confrontación armada para que se apliquen alli los estándares del Derecho Internacional Humanitario"s5; que "no es necesario probar que hubo un conflicto armado en todas y cada una de las pulgadas cuadradas del área en general. El estado de conflicto armado no se limita a las áreas de combate militar efectivo, sino que existe a lo ancho de todo el territorio bajo control de las partes en guerra" "86; y así mismo, que en el caso específico de los conflictos armados internos, el Derecho Internacional Humanitario se aplica desde su iniciación hasta el logro de un arreglo pacífico, en "todo el territorio bajo el control de una de las partes, sea que alli se desarrollen los combates como tales o no" 87 . De tal manera, cuando se trata de hechos o situaciones que tienen lugar en lugares donde no se desarrollan directamente los combates, para la aplicación del Derecho Internacional Humanitario

84 Traducción informal: "It is not necessary to establish the existence of an armed conflict within each municipality concerned. It suffices to establish the existence of the conflict within the whole region of which the municipalities are a part." Tribunal Penal para la Antigua Yugoslavia, Caso del Fiscal vs. Tihomir Blaskic, sentencia del 3 de marzo del 2000. Reiterado en el caso del Fiscal vs. Enver Hadzihasanovic y Amir Kubura, sentencia del 15 de marzo de 2006.

85 Ibid.

86 Traducción informal: "the Prosecutor did not have to prove that there was an armed conflict in each and every square inch of the general area. The state of armed conflict is not limited to the areas of actual military combat but exists across the entire territory under the control of the warring parties.” Tribunal Penal para la Antigua Yugoslavia, caso del Fiscal vs. Dragoljub Kunarac y otros, sentencia de la sala de apelaciones del 12 de junio de 2002.

87 Traducción informal: "International humanitarian law applies from the initiation of such armed conflicts and extends beyond the cessation of hostilities until a general conclusion of peace is reached; or, in the case of internal conflicts, a peaceful settlement is achieved. Until that moment, international humanitarian law continues to apply in the whole territory of the warring States or, in the case of internal conflicts, the whole territory under the control of a party, whether or not actual combat takes place there". Tribunal Penal para la Antigua Yugoslavia, Caso del Fiscal v. Dusko Tadic, No. IT-94-1-AR72, decisión de la Sala de Apelaciones sobre su propia jurisdicción, 2 de octubre de 1995. En igual sentido, ha afirmado este tribunal que "el marco geográfico y temporal de este test también es jurisprudencia consolidada: los crímenes cometidos en cualquier lugar del territorio bajo el control de una parte del conflicto, hasta que se logre un arreglo pacífico del conflicto, caen bajo la jurisdicción del Tribunal" [Traducción informal: "The geographic and temporal framework of this test is also settled jurisprudence: crimes committed anywhere in the territory under the control of a party to a conflict, until a peaceful settlement of the conflict is achieved, fall within the jurisdiction of the Tribunal.” Tribunal Penal para la Antigua Yugoslavia, caso del Fiscal vs. Fatmir Limaj y otros, sentencia del 30 de noviembre de 2005.] Regla reiterada en los casos de Fiscal vs. Sefer Halilovic, sentencia del 16 de noviembre de 2005; Fiscal vs. Momcilo Krajisnik, sentencia del 27 de septiembre de 2006. 
"sería suficiente (...) que los crimenes alegados estuviesen relacionados de cerca con las hostilidades desarrolladas en otras partes de los territorios controlados por las partes del conflicto"88.

1.2.3. En términos materiales, para que un determinado hecho o situación que ha ocurrido en un lugar en el que no se han desarrollado los combates armados quede cubierto bajo el ámbito de aplicación del Derecho Internacional Humanitario, es necesario que tal hecho o situación guarde una relación cercana y suficiente con el desarrollo del conflicto ${ }^{89}$. Así, no todos los hechos ilícitos que ocurren durante un conflicto armado se someten al derecho internacional humanitario; "solo aquellos actos suficientemente relacionados con el desarrollo de las hostilidades están sujetos a la aplicación de este derecho. (...) Es necesario concluir que el acto, que bien podría ser cometido en ausencia de un conflicto, fue perpetrado contra la víctima o víctimas afectadas por razón del conflicto en cuestión". ${ }^{90}$ La jurisprudencia internacional ha proporcionado distintos criterios para determinar la existencia de un nexo cercano entre un determinado hecho o situación y el conflicto armado internacional o interno en el que ha tenido lugar; así, ha señalado que tal relación cercana existe "en la medida en que el crimen sea moldeado por o dependiente del ambiente en el

88 Traducción informal: "it would be sufficient (...) that the alleged crimes were closely related to hostilities occurring in other parts of the territories controlled by the parties to the conflict." Tribunal Penal para la Antigua Yugoslavia, caso del Fiscal vs. Dragoljub Kunarac y otros, sentencia de la sala de apelaciones del 12 de junio de 2002. Igual regla fue aplicada en los casos de Fiscal vs. Dusko Tadic, anteriormente citado; Fiscal vs. Radoslav Brdjanin, sentencia del $1^{\circ}$ de septiembre de 2004; Fiscal vs. Mladen Naletilic y Vinko Martinovic, sentencia del 31 de marzo de 2003; Fiscal vs. Enver Hadzihasanovic y Amir Kubura, sentencia del 15 de marzo de 2006; y Fiscal vs. Sefer Halilovic, sentencia del 16 de noviembre de 2005.

89 El Tribunal Penal para la Antigua Yugoslavia ha considerado que la "relación requerida" se satisface cuandoquiera que los crímenes denunciados están "relacionados de cerca con las hostilidades" ["closely related to the hostilities"; Caso del Fiscal v. Dusko Tadic, No. IT-94-1-AR72, decisión de la Sala de Apelaciones sobre su propia jurisdicción, 2 de octubre de 1995], cuando existe un "vínculo obvio" entre ellos ["an obvious link"; caso del Fiscal vs. Zejnil Delalic y otros (caso Celebici), sentencia del 16 de noviembre de 1998], un "nexo claro" entre los mismos ["a clear nexus"; id.]; o un "nexo evidente entre los crímenes alegados y el conflicto armado como un todo" ["evident nexus between the alleged crimes and the armed conflict as a whole"; caso del Fiscal vs. Tihomir Blaskic, sentencia del 3 de marzo del 2000].

90 Traducción informal: "Not all unlawful acts occurring during an armed conflict are subject to international humanitarian law. Only those acts sufficiently connected with the waging of hostilities are subject to the application of this law. (...) It is necessary to conclude that the act, which could well be committed in the absence of a conflict, was perpetrated against the victim(s) concerned because of the conflict at issue." Tribunal Penal para la Antigua Yugoslavia, caso del Fiscal vs. Aleksovsky, sentencia del 25 de junio de 1999. 
que se ha cometido-v.g. el conflicto armado- ${ }^{\prime 91}$. Al determinar la existencia de dicha relación las cortes internacionales han tomado en cuenta factores tales como la calidad de combatiente del perpetrador, la calidad de no combatiente de la víctima, el hecho de que la víctima sea miembro del bando opuesto, el hecho de que el acto pueda ser visto como un medio para lograr los fines últimos de una campaña militar, o el hecho de que el acto haya sido cometido como parte de los deberes oficiales del perpetrador, o en el contexto de dichos deberes $^{92}$. También ha precisado la jurisprudencia, en casos de comisión de crímenes de guerra, que es suficiente establecer que "el perpetrador actuó en desarrollo o bajo la apariencia del conflicto armado", y que "el conflicto no debe necesariamente haber sido la causa de la comisión del crimen, sino que la existencia del conflicto debe haber jugado, como mínimo, una parte

91 Traducción informal: "Such a relation exists as long as the crime is 'shaped by or dependent upon the environment - the armed conflict - in which it is committed." Tribunal Penal para la Antigua Yugoslavia, caso del Fiscal vs. Blagojevic y Jokic, sentencia del 17 de enero de 2005. En igual sentido ha explicado este tribunal que "lo que distingue en últimas a un crimen de guerra de un delito puramente doméstico, es que el crimen de guerra es moldeado por o dependiente del ambiente en el cual se ha cometido -el conflicto armado-" [Traducción informal: "What ultimately distinguishes a war crime from a purely domestic offence is that a war crime is shaped by or dependent upon the environment - the armed conflict - in which it is committed". Tribunal Penal para la Antigua Yugoslavia, caso del Fiscal vs. Dragoljub Kunarac y otros, sentencia de la Sala de Apelaciones del 12 de junio de 2002].

92 Traducción informal: "59. In determining whether or not the act in question is sufficiently related to the armed conflict, the Trial Chamber may take into account, inter alia, the following factors: the fact that the perpetrator is a combatant; the fact that the victim is a non-combatant; the fact that the victim is a member of the opposing party; the fact that the act may be said to serve the ultimate goal of a military campaign; and the fact that the crime is committed as part of or in the context of the perpetrator's official duties." Tribunal Penal para la Antigua Yugoslavia, caso del Fiscal vs. Dragoljub Kunarac y otros, sentencia de la sala de apelaciones del 12 de junio de 2002. En igual sentido afirmó este Tribunal que "al determinar si dicho nexo existe, la Sala puede tomar en consideración, entre otros, el hecho de que el perpetrador sea un combatiente, el que la victima sea un no-combatiente, el que la víctima sea miembro de la parte contraria, el que pueda decirse que el acto haya contribuido a la meta última de la campaña militar, o el que el crimen se haya cometido como parte o en el contexto de los deberes oficiales del perpetrador" [Traducción informal: "In determining whether such nexus exists the Chamber may take into account, inter alia, whether the perpetrator is a combatant, whether the victim is a non-combatant, whether the victim is a member of the opposing party, whether the act may be said to serve the ultimate goal of a military campaign, and whether the crime is committed as part of or in the context of the perpetrator's official duties.' Tribunal Penal para la Antigua Yugoslavia, caso del Fiscal vs. Fatmir Limaj y otros, sentencia del 30 de noviembre de 2005].

93 Traducción informal: "the perpetrator acted in furtherance of or under the guise of the armed conflict". Tribunal Penal para la Antigua Yugoslavia, caso del Fiscal vs. Dragoljub Kunarac y otros, sentencia de la sala de apelaciones del 12 de junio de 2002. 
sustancial en la capacidad del perpetrador para cometerlo, en su decisión de cometerlo, en la manera en que fue cometido o en el objetivo para el que se cometió $^{94, "}$.95

En síntesis, para determinar si una conducta infringió el derecho internacional humanitario (y en el mismo sentido, si son aplicables las normas del Código Penal que tipifican los delitos contra las personas y bienes protegidos por dicha normativa), deben observarse los siguientes criterios:

i) Criterio temporal: El DIH se aplica desde la iniciación del conflicto y se extiende más allá del cese de las hostilidades, hasta la consecución de la paz, o por lo menos hasta cuando se dan arreglos pacíficos entre los grupos armados en contienda.

ii) Criterio geográfico, de acuerdo con el cual la normativa humanitaria debe respetarse en:

- Aquellos lugares donde se desarrollan combates u hostilidades;

- La totalidad del territorio controlado por los grupos armados enfrentados;

- Otros lugares donde no hay confrontación, siempre que los actos perpetrados estén relacionados con el conflicto armado. ${ }^{96}$

94 Traducción informal: "the armed conflict need not have been causal to the commission of the crime, but that the existence of an armed conflict must, at a minimum, have played a substantial part in the perpetrator's ability to commit it, his decision to commit it, the manner in which it was committed or the purpose for which it was committed". Tribunal Penal para la Antigua Yugoslavia, casos de Fiscal vs. Enver Hadzihasanovic y Amir Kubura, sentencia del 15 de marzo de 2006, y Fiscal vs. Sefer Halilovic, sentencia del 16 de noviembre de 2005 -ambos reiterando lo decidido en el caso del Fiscal vs. Dragoljub Kunarac y otros, sentencia de la sala de apelaciones del 12 de junio de 2002Ver en igual sentido el pronunciamiento de este Tribunal en el caso Limaj: "No es necesario que el conflicto armado haya sido la causa de la commission del crimen que se acusa, pero sí debe haber jugado un rol sustancial en la capacidad del perpetrador para cometerlo" [Traducción informal: "The armed conflict need not have been causal to the commission of the crime charged, but it must have played a substantial part in the perpetrator's ability to commit that crime." Tribunal Penal para la Antigua Yugoslavia, caso del Fiscal vs. Fatmir Limaj y otros, sentencia del 30 de noviembre de 2005].

95 Corte Constitucional, Sentencia C-291 del 25 de abril de 2007. M.P. Manuel José Cepeda Espinosa.

96 En este sentido ha expresado la Comisión Interamericana de Derechos Humanos:

La Comisión también desea hacer énfasis en que, en conflictos armados internos, el derecho humanitario se aplica en todo el territorio nacional, no solamente en áreas geográficas específicas donde se llevan a cabo las hostilidades. Por consiguiente, cuando el derecho humanitario prohíbe a las partes del conflicto dirigir ataques contra personas civiles o tomar rehenes en cualquier circunstancia, prohíbe dichos actos en todas partes. Por lo tanto, dichos actos de violencia cometidos por las partes en áreas en las que no hay hostilidades no son menos violatorios del derecho internacional humanitario que aquellos que se cometen en las zonas más conflictivas del país. En CIDH, Tercer Informe sobre la situación de derechos humanos en Colombia, Washington, D.C, 1999, párr. 83. Citado por Alejandro Valencia Villa, Op.cit. 
iii) Criterio material: El DIH es aplicable siempre que un hecho denote relación cercana con el desarrollo del conflicto. Para establecer esta relación pueden acreditarse los siguientes factores:

- Calidad de combatiente del perpetrador;

- Calidad de no combatiente de la víctima, o

- Que la víctima sea miembro del bando opuesto;

- Que el acto pueda ser percibido como un medio para lograr los fines del grupo armado, o como parte de su estrategia ${ }^{97}$ o ideología;

- Que el acto haya sido cometido como parte de los deberes oficiales del perpetrador o en el contexto de los mismos.

- Que no existan móviles personales para la ejecución del delito.

En términos de la Corte Suprema de Justicia ${ }^{98}$, la constatación de que la conducta de violencia sexual se produjo en el seno de un conflicto armado es fundamental, más no suficiente, al determinar su vinculación con el mismo ${ }^{99}$. Para demostrar esta vinculación es preciso verificar que la existencia del conflicto armado jugó un papel sustancial en:

a) la decisión del autor de realizar la conducta (por ejemplo, porque obedece a una táctica de guerra contra el bando enemigo o de dominación a la población).

b) la capacidad del autor para llevarla a cabo (aún cuando la práctica en sí misma no obedezca a una finalidad relacionada con el conflicto, el perpetrador puede valerse de su condición de miembro de un grupo armado y del temor y dominación que esto infunde sobre la población, como mecanismo de coacción para que las mujeres accedan a sus exigencias sexuales);

c) la manera de ejecutarla (por ejemplo, en el marco de retenciones o masacres perpetradas contra la población).

97 Esto puede implicar la existencia de patrones de actuación criminal.

98 Corte Suprema de Justicia, Proceso No. 32022, Auto del 21 de septiembre de 2009, M.P. Sigifredo Espinosa Pérez. Citando a Héctor Olásolo en "Ensayos sobre la Corte Penal Internacional".

99 En el mismo sentido, TPIR, Prosecutor v. Clement Kayishema and Obed Ruzindana:

"La Sección es de la opinión que solo las ofensas que tienen relación con el conflicto armado comprenden esta categoría. Si no hay una relación directa entre los crímenes y el conflicto armado no hay bases para concluir que el artículo $3^{\circ}$ Común y el Protocolo II han sido violados... El término "nexo" no debe ser entendido como algo vago e indefinido. Una relación directa entre los crímenes invocados, referidos en la acusación, y el conflicto armado debe ser establecida teniendo en cuenta los hechos ocurridos. Sin evaluación, por lo tanto, no puede ser definido en abstracto. Teniendo en cuenta caso por caso, la Sección de Primera Instancia adjudica los hechos ocurridos hasta donde existe una relación. Es de la incumbencia de la Fiscalía el presentar esos hechos y probar, más allá de la duda, la existencia de dicho nexo (o relación). Citado en Valencia Villa, Alejandro, Op. cit. 
Para determinar las condiciones antes mencionadas en relación con los delitos sexuales, es necesario conocer los contextos de comisión de violencia sexual que se han identificado en el marco del conflicto armado colombiano. La Corporación Humanas ha identificado los siguientes ${ }^{100}$ :

a) Actos cometidos en el marco de ataques simples o sistemáticos contra una población (p. ej. la perpetración de una masacre) o contra alguno de sus miembros (p. ej. ataque de carácter sexual contra una mujer de la comunidad por parte de uno o más miembros de uno de los grupos armados en contienda).

b) Actos perpetrados bajo el control territorial de un grupo armado sobre una determinada región, en los cuales la autoridad y la posición militar ejercida por dicho grupo son aprovechadas por sus miembros para cometer este tipo de actos.

c) Violencia sexual cometida en situaciones de privación de la libertad de la víctima, es decir, cuando la misma se encuentra detenida, retenida o secuestrada. Bajo estas circunstancias, se encuentra viciada la capacidad de la víctima para consentir el acto sexual.

d) Actos perpetrados al interior de los grupos armados, en contra de sus integrantes (por ejemplo, anticoncepción forzada).

También resulta fundamental identificar las finalidades a que pueden obedecer este tipo de actos en el marco del conflicto armado. Remitiéndonos nuevamente a la Corporación Humanas ${ }^{101}$, estas finalidades pueden ser:

i) Dominar o demostrar superioridad sobre quien se ejerce (o sobre su familia o comunidad);

ii) Regular las relaciones y comportamientos de una comunidad, particularmente de aquellos relacionados con sus relaciones sexuales o afectivas;

iii) Disuadir a una persona $\mathrm{u}$ organización a continuar adelantando procesos de reclamación de derechos;

iv) Obtener información que pueda darle ventajas sobre sus enemigos;

v) castigar a quienes desobedecen sus órdenes o pertenecen o sostienen algún vínculo con el enemigo;

vi) Expulsar a una persona, su familia o comunidad de un determinado territorio, buscando apoderarse de sus tierras o bienes o alcanzar un mayor control sobre la zona;

100 En Caicedo Delgado, L., Buenahora Streithorst, N., Benjumea Rúa, A. (2009). Guía para llevar casos de violencia sexual. Propuestas de argumentación para enjuiciar crimenes de violencia sexual cometidos en el marco del conflicto armado colombiano. Corporación Humanas - Centro Regional de Derechos Humanos y Justicia de Género. Bogotá, Colombia. 
vii) Hacer desaparecer una organización, un grupo social o político, mediante el ataque a sus miembros o allegados;

viii) Recompensar, subir la moral o incentivar a los miembros de un grupo armado, mediante el disfrute sexual;

ix) Mantener la unidad, el control y la disciplina al interior del grupo armado.

En términos generales, puede afirmarse que un acto de violencia sexual está vinculado al conflicto armado cuando ocurrió en el marco de alguno de los contextos previamente señalados, o persiguió alguna de las finalidades mencionadas.

\section{d. Sujeto pasivo}

El tipo penal de esclavitud sexual exige que la conducta sea cometida contra "persona protegida".

El Código Penal define esta calidad en los siguientes términos:

Artículo 135. Parágrafo. Para los efectos de este artículo y las demás normas del presente título se entiende por personas protegidas conforme al derecho internacional humanitario: 1. Los integrantes de la población civil. 2. Las personas que no participan en hostilidades y los civiles en poder de la parte adversa. 3. Los heridos, enfermos o náufragos puestos fuera de combate. 4. El personal sanitario o religioso. 5. Los periodistas en misión o corresponsales de guerra acreditados. 6. Los combatientes que hayan depuesto las armas por captura, rendición u otra causa análoga. 7. Quienes antes del comienzo de las hostilidades fueren considerados como apátridas o refugiados. 8. Cualquier otra persona que tenga aquella condición en virtud de los Convenios I, II, III y IV de Ginebra de 1949 y los Protocolos Adicionales I y II de 1977 y otros que llegaren a ratificarse". (Cursivas fuera del original)

Sin perjuicio que de las víctimas del delito de esclavitud sexual puedan pertenecer a las demás categorías señaladas en la citada norma, resulta relevante examinar la categoría de población civil a que se refiere el numeral $1^{\circ}$.

La Corte Constitucional ha sostenido que:

"Para los efectos del principio de distinción en su aplicación a los conflictos armados internos, el término "civil" se refiere a las personas que reúnen las dos condiciones de (i) no ser miembros de las fuerzas armadas $u$ organizaciones armadas irregulares enfrentadas y (ii) no tomar parte en las hostilidades, sea de manera individual como "personas civiles" o "individuos civiles", o de manera colectiva en tanto "población civil". ${ }^{102}$

De esta manera, lo que debe demostrarse para la configuración de los delitos contra las personas y bienes protegidos por el derecho internacional

102 Corte Constitucional, Sentencia C-291 del 25 de abril de 2007. M.P. Manuel José Cepeda Espinosa. 
humanitario es que al momento de comisión de los hechos, la víctima no estaba realizando conductas que pudieran se consideradas como participación directa en las hostilidades. El tomar parte en las hostilidades de manera directa implica la pérdida de la inmunidad que otorga el derecho internacional humanitario a los civiles (aún cuando conservan su calidad de civiles) y los hace objeto lícito de ataques ${ }^{103}$.

Subraya el Comité Internacional de la Cruz Roja que cualquier persona que participe indirectamente en las hostilidades, es decir, a través de actos que no impliquen violencia o amenaza de daño actual contra la contraparte (por ejemplo, actuando como mensajeros o vendiendo mercadería a una o a varias partes en conflicto), conserva la calidad de persona protegida ${ }^{104}$.

\section{e. La conducta: "obligar a prestar servicios sexuales"}

La prestación de servicios sexuales bajo ciertas circunstancias coercitivas que anulan la autonomía personal de sus víctimas reduciéndolas a la condición de objetos, constituye una de las formas contemporáneas de esclavitud. De esta manera, la configuración de este tipo penal exige probar, de una parte, los actos sexuales realizados por la víctima, y de otra, que la conducta del victimario de obligar a la misma a que ejecute tales actos es de alguna manera "calificada" para reducir a la misma a una condición de esclavitud (esto es lo que permite establecer la diferencia con el acceso carnal violento o los actos sexuales abusivos; a su vez, es la realización de actos sexuales bajo este contexto lo que permite diferenciar la esclavitud sexual de otras modalidades de esclavitud).

Desde su consagración como delito, ningún caso que se ajuste a la descripción típica de esclavitud sexual ha sido de conocimiento de la Corte Suprema de Justicia. La Corte Constitucional tampoco se ha referido a esta práctica en su jurisprudencia.

No obstante, existen algunos pronunciamientos de la Corte Constitucional en relación con la prohibición de la esclavitud consagrada en el artículo 17 de la Carta, que permiten establecer el alcance de esta disposición. Vale destacar en este sentido, las sentencias T - 498 de 1994 y T - 1299 de 2000, en las cuales la Corte advirtió que:

"El artículo 17 de la Constitución garantiza la libertad física de la persona humana mediante la prohibición de la esclavitud, la servidumbre y la trata de seres humanos en todas sus formas. La dignidad de la persona humana no permite que ésta sea reducida a la condición de cosa u objeto, carente de autonomía, lo que sucede cuando por actos particulares se dispone de la libertad o del cuerpo de un ser humano".

Esta interpretación de la Corte permite establecer que:

i) La esclavitud puede ser entendida como un acto a través del cual se reduce a una persona a la condición de cosa u objeto.

103 Comité Internacional de la Cruz Roja, Comentario Protocolo I, tomo II, párr. 1944.

104 Ibid. 
ii) La esclavitud, implica además, la anulación de la autonomía personal.

iii) Disponer de la libertad o del cuerpo de un ser humano constituye un acto de esclavitud.

El derecho internacional humanitario, por su parte, no hace expresa a referencia al concepto de esclavitud sexual en el marco de conflictos armados, pero sí incorpora algunas disposiciones que, de una parte, consagran el derecho de las personas que no participan directamente en las hostilidades a recibir un trato humano, y de otra, prohíben los atentados contra la dignidad, salud e integridad personales, así como aquellos actos que atenten contra el honor y el pudor, bienes jurídicos que resultan afectados con la comisión de esta práctica ${ }^{105}$ (artículo 3 común a los Convenios de Ginebra y artículo 4 del Protocolo Adicional II). Adicionalmente, se prohíben expresamente la esclavitud y la trata de esclavos en todas sus formas, la violación y la prostitución forzada, que es, a su vez, una forma de esclavitud (Protocolo II, artículo 4$)^{106}$

Por su parte, la Convención sobre la Esclavitud ${ }^{107}$ establece en su artículo $1^{\circ}$, que para los fines de dicho instrumento, "la esclavitud es el estado o condición de un individuo sobre el cual se ejercitan los atributos del derecho de propiedad o algunos de ellos". La misma definición es utilizada por la Convención suplementaria sobre la abolición de la esclavitud, la trata de esclavos y las instituciones y prácticas análogas a la esclavitud ${ }^{108}$, en su artículo $7 .{ }^{109}$

105 En el Protocolo Adicional II, los actos de violencia sexual son definidos como atentados contra la dignidad personal y el pudor (artículo 4, numeral $2^{\circ}$, literal e). De manera similar, en el Código Penal colombiano de 1936 el bien jurídico que se protegía en los delitos sexuales era la libertad y el honor sexual y en el de 1980, la libertad y el pudor sexual. No obstante, de manera más adecuada, a partir de la expedición de la Ley 360 de 1997 "se les denominó delitos contra la libertad sexual y la dignidad humana, suprimiendo la expresión pudor porque ninguno de los tipos penales se orientaba a proteger el recato o la vergüenza del acto sexual y porque el pudor no se podía considerar como bien jurídico por tratarse de un sentimiento (...). Corte Suprema de Justicia, Sala de Casación Penal. Proceso No. 25.743, sentencia del 08 de octubre de 2008, M.P. Álvaro Orlando Pérez Pinzón.

106 De igual manera, el artículo 27 del Convenio IV de Ginebra estipula que en el marco de conflictos armados, las mujeres deben ser "especialmente protegidas contra cualquier ataque sobre su honor, en particular contra la violación, prostitución forzada, o cualquier forma de ataque sexual indecente. $(\ldots) "$

107 Suscrita el 25 de septiembre de 1926 y entrada en vigor el 9 de marzo de 1927.

108 Adoptada el 30 de abril de 1956 y entrada en vigor el 30 de abril de 1957.

109 Esta misma definición fue adoptada por la Comisión de Derecho Internacional de Naciones Unidas en el Proyecto de Código de Crímenes contra la Paz y la Seguridad de la humanidad de 1996 (el trabajo de la Comisión es considerado como evidencia dela costumbre internacional). Otros tratados de derecho internacional se refieren a la esclavitud o conceptos relacionados sin proveer explícitamente una definición (entre ellos, la Declaración Universal de los Derechos Humanos de 1948, el Pacto Internacional de Derechos Civiles y Políticos de 1966, la Convención Europea de Derechos Humanos y Libertades Fundamentales de 1950, la Convención Americana de Derechos Humanos de 1969 y el Estatuto Africano de Derechos Humanos y de los Pueblos de 1981). 
En 1998, la Relatora Especial de Naciones Unidas sobre la violación sistemática, la esclavitud sexual y las prácticas análogas de esclavitud en tiempo de conflicto armado - Gay J. McDougall- presentó su informe final a la Comisión de Derechos Humanos $^{110}$. En el mismo, parte de la definición adoptada en la Convención sobre la Esclavitud, afirmando que esta práctica debe ser entendida como "el estado o condición de una persona sobre quien alguno o todos los poderes atribuidos al derecho de propiedad son ejercidos, incluyendo el acceso carnal a través de la violación u otras formas de violencia sexual"111. Aclara la relatora que si bien la esclavitud requiere el trato de una persona como propiedad privada, el hecho de que una persona no hubiera sido comprada, vendida o comercializada no puede, de ninguna manera, desvirtuar una acusación de esclavitud.

La relatora indica en su informe que en la definición de esclavitud están implícitas nociones concernientes a limitaciones en la autonomía, la libertad de movimiento y el poder de decidir por sí mismo/a cuestiones relativas a su sexualidad.

Asimismo, afirma que "la mera capacidad para librarse, aún bajo un riesgo sustancial de daño personal, de una condición de esclavitud, no deberá anular un alegato de esclavitud".

La Relatora establece, además, que en todo caso en el que se alegue esclavitud, debe ser aplicado un análisis con conciencia de género en la interpretación de si es razonable el temor de la persona esclavizada a sufrir un daño o su percepción de la coerción. Esto es particularmente cierto cuando la víctima se encuentra en una zona de combate durante un conflicto armado, sea interno o internacional, y ha sido identificada como miembro del bando enemigo.

Explica la relatora que el término "sexual" constituye un adjetivo que describe una forma de esclavitud; bajo toda consideración y en todas las circunstancias, la esclavitud sexual es esclavitud y su prohibición es norma de jus cogens.

Por su parte, el Estatuto de Roma consagra por primera vez la esclavitud sexual como crimen de guerra y de lesa humanidad (artículos 7 1) g) 2 y 8 2) b) xxii) 2). En los Elementos de Crímenes de la Corte (artículo 7 1) g) 2), se señalan los elementos que configuran este crimen:

1. Que el autor haya ejercido uno de los atributos del derecho de propiedad sobre una o más personas, como comprarlas, venderlas, prestarlas o darlas en trueque, o todos ellos, o les haya impuesto algún tipo similar de privación de libertad.

2. Que el autor haya hecho que esa o esas personas realizaran uno o más actos de naturaleza sexual.

110 Subcomisión para la Prevención de la Discriminación y Protección de las Minorías, $50^{\circ}$ periodo de sesiones. E/CN.4/Sub.2/1998/13.

111 Traducción no oficial. 
3. Que la conducta se haya cometido como parte de un ataque generalizado o sistemático dirigido contra una población civil.

4. Que el autor haya tenido conocimiento de que la conducta era parte de un ataque generalizado o sistemático dirigido contra una población civil o haya tenido la intención de que la conducta fuera parte de un ataque de ese tipo. ${ }^{112}$

En general, esta definición establece los dos elementos esenciales de la esclavitud sexual:

i) El ejercicio de los atributos de la propiedad sobre una persona y

ii) La realización de actos de violencia sexual bajo este contexto.

Para mayor claridad, puede resultar útil recurrir a la legislación civil colombiana a fin de establecer el alcance del derecho de dominio o propiedad. De acuerdo con el Art. 669 del Código Civil, "el dominio (que se llama también propiedad) es el derecho real en una cosa corporal, para gozar y disponer de ella, no siendo contra la ley o contra derecho ajeno".

Evidentemente, esta disposición se refiere al ejercicio del derecho de dominio sobre cosas corporales y no sobre personas, que tenga la calidad de lícito; sin embargo, los atributos de la propiedad en ella señalados son aplicables para cualquier ejercicio de ella-lícito o ilícito-.

La atribución de gozar corresponde al derecho de usufructo (como se le denomina en derecho civil), es decir, el derecho de servirse de una cosa según su naturaleza y destino, y comprende, a su vez, las facultades de usar y disfrutar la cosa. El derecho de uso está limitado a la satisfacción de las necesidades del usuario; por su parte, el derecho de disfrutar o usufructuar, permite al usufructuario hacer suyos los frutos que genera el bien. La facultad de disposición comprende, entre otros, el derecho a enajenar o constituir gravámenes sobre el bien.

El provecho económico o de otro tipo que caracteriza la práctica de prostitución forzosa corresponde de esta manera, a la facultad de usufructuar a la persona prostituida $^{113}$. Es aquí, justamente donde radica la diferencia entre esclavitud sexual y prostitución forzosa.

Al respecto ha dicho la Relatora especial de Naciones Unidas sobre la violación sistemática, la esclavitud sexual y las prácticas análogas de esclavitud en tiempo de conflicto armado, que la esclavitud abarca la mayoría, si no todas las formas de prostitución forzada. De acuerdo con la Relatora, la prostitución forzada generalmente se refiere a condiciones de control sobre una persona que es coercionada por otra a contratar en actividades sexuales.

112 Los dos últimos elementos describen el contexto en que debe tener lugar la conducta para configurar el crimen de lesa humanidad (Corte Constitucional, Sentencia C-801 de 2009). El artículo 8) 2) b) xxii) 2, por su parte, indica los elementos que configuran el crimen de guerra de esclavitud sexual.

113 Asimismo, puede afirmarse que la trata de personas que comprende el comercio de las mismas, corresponde al ejercicio de la facultad de disposición. La trata de personas es considerada una forma contemporanea de esclavitud. 
La prostitución forzada fue consagrada como crimen de lesa humanidad y crimen de guerra en el Estatuto de la Corte Penal Internacional (artículos 7) 1) g) 3 y 8) 2) b) xxii) 3). Los Elementos de Crímenes de la Corte señalan que la misma se configura cuando se dan los siguientes elementos:

1. Que el autor haya hecho que una o más personas realizaran uno o más actos de naturaleza sexual por la fuerza, o mediante la amenaza de la fuerza o mediante coacción, como la causada por el temor a la violencia, la intimidación, la detención, la opresión psicológica o el abuso de poder contra esa o esas personas u otra persona, o aprovechando un entorno de coacción o la incapacidad de esa o esas personas de dar su consentimiento genuino.

2. Que el autor u otra persona hayan obtenido, o esperaran obtener, ventajas pecuniarias o de otro tipo a cambio de los actos de naturaleza sexual o en relación con ellos.

$$
\text { (...) }
$$

De acuerdo con lo anterior, es claro que aunque la prostitución forzada es una forma de esclavitud sexual, el lucro constituye el elemento que la diferencia de otras modalidades de esta práctica.

Volviendo a los elementos que permiten configurar el crimen de esclavitud sexual, debe precisarse que la jurisprudencia internacional en esta materia es escasa ${ }^{114}$. Aún

114 Existen algunas referencias jurisprudenciales en materia de otras formas de esclavitud. Por ejemplo, el procesado en el caso Milch ante el Tribunal Militar US fue acusado de trabajos forzados y deportación para trabajos forzados de nacionales alemanes y nacionales de otros países como un crimen contra la humanidad. El Tribunal observó que las víctimas estuvieron privadas de sus derechos civiles básicos: "ellos fueron privados del derecho a moverse libremente o escoger su lugar de residencia; vivir en un hogar con sus familias; criar y educar a sus hijos; casarse; visitar lugares públicos de su propia elección; negoriar, por sí mismos o a través de representantes de su elección, sus propias condiciones de empleo; organizarse en sindicatos o agremiaciones; ejercer la libertad de expresión u opinión; reunirse en asambleas pacíficas; y fueron frecuentemente privados de su derecho de su derecho a adorar de acuerdo con sus creencias. Todos estos son indicios de esclavitud, no de un libre empleo bajo contrato". Este mismo tribunal sostuvo en el caso Pohl, que "La esclavitud puede existir incluso sin tortura. Los esclavos pueden estar bien alimentados, bien vestidos y alojados confortablemente, pero siguen siendo esclavos cuando, sin un debido proceso legal, son privados de su libertad mediante fuertes restricciones. Podríamos anular toda prueba de malos tratos, hacer caso omiso del hambre, los golpes y otros actos bárbaros, pero el hecho de esclavitud y trabajos obligatorios incompensados permanecería aún. No existe algo tal como esclavitud benévola. La servidumbre involuntaria, incluso si fue atenuada por un trato humano, es esclavitud. Por su parte, la Comisión Europea de Derechos Humanos observó en el caso Van Droogenbroeck v Belgium, que "además de la obligación de desempeñar ciertos servicios para otros, la noción de servidumbre abarca la obligación para el siervo de vivir bajo la propiedad de otra persona y la imposibilidad de cambiar su condición" (CEDH, Decisión del 5 de julio de 1979, D/R 17, 59). Estas decisiones fueron citadas por el Tribunal Penal para la Antigua Yugoslavia, caso del Fiscal vs. Dragoljub Kunarac y otros, sentencia de la sala de juzgamiento del 22 de febrero de 2001. (Traducción de la autora) 
cuando prácticas de esta naturaleza se ejecutaron sistemáticamente en muchos de los conflictos armados del siglo $\mathrm{XX}^{115}$, muy pocos casos han sido judicializados ante instancias de carácter internacional.

Vale la pena revisar en este sentido, la decisión del Tribunal Penal Internacional para la Antigua Yugoslavia en el caso Foca (El Fiscal vs. Kunarac y otros) ${ }^{116}$, en la cual se estructuraron de manera mucho más específica, los elementos que permiten establecer la configuración de esta práctica. El Tribunal sostuvo en este caso, lo siguiente:

“539. (...) en el momento relevante para el escrito de acusación, la esclavitud como crimen contra la humanidad en la costumbre internacional consistía en el ejercicio de uno o todos los poderes adjuntos al derecho de propiedad sobre una persona.

540. De este modo, la Sala de Apelaciones encuentra que el actus reus de la violación es el ejercicio de cualquiera o todos los poderes adjuntos al derecho de propiedad sobre una persona. El mens rea de la violación consiste en el ejercicio intencional de tales poderes.

\section{(...)}

542. Bajo esta definición, los indicios de esclavitud incluyen elementos de control y propiedad; la restricción o control de la autonomía individual, la libertad de elegir y la libertad de movimiento; y, a menudo, la acumulación de algún beneficio o ganancia para el perpetrador.

(...)

115 Las estaciones confort que fueron mantenidas por los militares japoneses durante la segunda guerra mundial, los campos de violación en la antigua Yugoslavia, las violaciones sistemáticas a las mujeres retenidas en los cuarteles de las interahamwe en Ruanda, matrimonios forzados en Ex Birmania (Myanmar) y Uganda, casos de esclavitud sexual en el marco de reclutamientos forzosos en Liberia y esclavitud sexual y doméstica en Guatemala.

116 En este caso, la acusación da cuenta de los siguientes hechos: FWS-186 y FWS-191 fueron mantenidas en una casa abandonada en Tronova-e, durante aproximadamente 6 meses, desde el 2 de agosto de 1992. Durante el tiempo de su detención, FWS-191 fue violada constantemente por Dragoljub Kunarac, mientras FWS-186 lo fue a manos de DP6. Las niñas fueron mantenidas en retención para ser usadas por Kunarac y DP6, prestando servicios sexuales a los mismos cada vez que regresaban a la casa. Kunarac reservó a FWS-191 para sí mismo (el acusado hizo valer esta exclusividad mediante la prohibición a otros soldados de violarla); las niñas fueron tratadas como propiedad personal de los acusados Kunarac y DP6. Adicionalmente, durante su retención, ellas fueron privadas de cualquier control sobre sus vidas, tuvieron que hacer tareas domésticas y obedecer todas las exigencias de sus victimarios. La madre de una de las víctimas testificó que uno de los acusados le comunicó que su hija estaba con él y que no podía devolvérsela; incluso, le permitió a la víctima escribirle una carta a su madre y a esta última le ordenó darle ropa a su hija. Las niñas no tenían libertad de movilidad; constató el tribunal que, aún cuando hubieran tenido las llaves de la casa, no tenían a donde ir y si hubieran intentado escapar no hubieran tenido donde esconderse (se constató que no tenían opciones en absoluto realistas de huir de la casa o escapar de sus agresores). 
Otros indicios de esclavitud, incluyen la explotación; la exacción de trabajos o servicios forzados u obligatorios, a menudo sin remuneración y de manera frecuente, aunque no necesariamente, involucra penurias físicas; sexo; prostitución; tráfico humano.

(...)

La adquisición o disposición de alguien para obtener una compensación monteria o de otro tipo, no es un requisito de la esclavitud. Hacer esto, no obstante, es un primer ejemplo del ejercicio del derecho a la propiedad sobre alguien. La duración del presunto ejercicio de los poderes atribuidos al derecho de propiedad es otro factor que puede ser considerdo cuando se determina si alguien fue esclavizado; sin embargo, su importancia puede depender en dado caso, de la existencia de otro indicio de esclavitud. Es más, detener o mantener a alguien en cautiverio, podría, dependiendo de las circunstancias del caso, no constituir esclavitud.

543. Por tanto, la Sala de Apelaciones está, en general, de acuerdo con los factores presentados por el fiscal, para que sean tomados en consideración en la determinación de si fue cometida esclavitud. Estos son el control de movimientos, el control del medio ambiente o entorno físico, el control psicológico, las medidas tomadas para prevenir o impedir el escape, el uso de la fuerza o la amenaza de fuerza o coerción, la duración, la afirmación de exclusividad, el sometimiento a tratos crueles y abusos, el control de la sexualidad y los trabajos forzados. El fiscal también sostuvo que la simple capacidad para comprar, vender, intercambiar o heredar a una persona o sus trabajos o servicios, podrían ser factores relevantes. La Sala de Apelaciones considera que la mera capacidad de hacerlo es insuficiente; pero que si dichas acciones están ocurriendo podría ser un factor relevante. (...)

733. (...) los periodos de tiempo exactos no requieren ser probados más allá de la duda razonable debido al contexto específico de guerra donde los crímenes concernientes ocurrieron." 117

De otra parte, es pertinente revisar la decisión de confirmación de cargos adoptada por la Corte Penal Internacional en el caso contra Germain Katanga y otro (situación de la República Democrática del Congo) ${ }^{118}$. En la misma, la Sala realizó

117 Tribunal Penal para la Antigua Yugoslavia, caso del Fiscal vs. Dragoljub Kunarac y otros, sentencia de la sala de apelaciones del 22 de febrero de 2001. (Traducción de la autora)

118 Germain Katanga es acusado de la esclavitud sexual de mujeres civiles residentes o presentes en la aldea de Bongoro (Colectividad de Bahema Sud, territorio de Irumu), bajo el artículo 8(2)(b)(xxii) del Estatuto. Los hechos ocurrieron con posterioridad al ataque perpetrado por el FNI y el FRPI el 24 de febrero de 2003 en la aldea de Bogoro. Durante el ataque, mujeres civiles fueron violadas y raptadas de la aldea, encarceladas y forzadas a convertirse en esposas de los combatientes del FNI/FRPI, exigiéndoles cocinar para ellos y participar en actos de naturaleza sexual. Otras mujeres fueron mantenidas en las prisiones de los campos militares (hoyos cavados en la tierra); allí fueron violadas en repetidas ocasiones por soldados y comandantes que se encontraban en el campo militar y también por soldados que eran castigados y enviados a prisión. 
algunas precisiones en torno al crimen de esclavitud sexual, que permiten determinar el alcance del mismo, afirmando lo siguiente:

“429. El crimen de lesa humanidad de esclavitud sexual según el artículo 7(1) (g) del Estatuto y artículo 7(1)(g)-2 de los Elementos de Crímenes, ocurre cuando:

i) el perpetrador ejerce uno o todos los atributos del derecho de propiedad sobre una o más personas, como comprarlas, venderlas, prestarlas o darlas en trueque, o imponer sobre ellas una privación similar de la libertad;

ii) el perpetrador haga que tal persona o personas participen o se involucren en uno o más actos de naturaleza sexual. Los ejemplos citados bajo el primer elemento no constituyen una lista exhaustiva.

430. La Sala anota que aunque la esclavitud sexual está incluida como una ofensa separada en el artículo 7(1)(g) del Estatuto, esta puede ser considerada una forma particular de esclavitud. Como corresponde, las notas al pie 11 (crimen contra la humanidad de Esclavitud) y 18 (crimen de lesa humanidad de esclavitud sexual) de los Elementos de Crímenes, indican que "esta privación de la libertad puede, en algunas circunstancias, incluir la exigencia de trabajos forzosos u otros tipos reduciendo a la persona a un estado servil como denota la Convención suplementaria sobre la abolición de la esclavitud, el comercio de esclavos, e instituciones y prácticas análogas a la esclavitud de 1956. La Convención Suplementaria enlista instituciones o prácticas que incluyen esclavitud por deudas, práctica de matrimonios forzados y formas de trabajo infantil, que constituyen particulares formas de esclavitud.

431. Desde el punto de vista de la Sala, la esclavitud sexual también rodea situaciones donde mujeres y niñas son forzadas en matrimonio, servidumbre doméstica u otro trabajo forzado que involucre actividad sexual obligatoria, incluida la violación, por sus captores. Formas de esclavitud sexual pueden ser, por ejemplo, "prácticas tales como la detención de mujeres en campos de violación o estaciones confort, matrimonios temporales forzados con soldados $y$ otras prácticas que involucran el trato de las mujeres como propiedad privada, y como tales, violaciones de la norma perentoria de prohibición de la esclavitud.

432. El Segundo elemento del crimen contra la humanidad de esclavitud sexual exige que "el perpetrador haga que tal persona o personas participen en uno o más actos de naturaleza sexual". De este modo, un parámetro particular del crimen de esclavitud sexual - sumado a limitaciones de la autonomía de la víctima y la libertad de movimiento- es la limitación de su capacidad de decidir sobre aspectos relacionados a su actividad sexual." 119

Finalmente, la Sala parte de la constatación de tres presupuestos fácticos para la confirmación de los cargos de esclavitud sexual: i) que las mujeres fueron raptadas o secuestradas, ii) que durante el cautiverio, los combatientes las utilizaron como sus esposas, y iii) que en este contexto, las forzaron y amenazaron para participar

119 Corte Penal Internacional. Decisión No. ICC-01/04-01/07 del 30 de septiembre de 2008. 
en relaciones sexuales. Partiendo de estos presupuestos, la Sala concluye que los acusados esclavizaron sexualmente a las mujeres de manera intencional, o sabían que al cometer tales actos, la esclavitud sexual podía ocurrir. ${ }^{120}$

A partir de las fuentes citadas puede establecerse como conclusión, que los elementos indicativos de la prestación forzada de servicios sexuales en contextos de esclavitud son los siguientes:

1. Que el autor haya ejercido uno o todos los atributos del derecho de propiedad sobre una persona, no solo en el sentido tradicional de explotación económica. El ejercicio del dominio o propiedad comprende los atributos de goce y disposición; a su vez, el poder de gozar comprende las facultades de usar y usufructuar.

A su vez, la esclavitud incluye elementos de restricción o control de la autonomía individual y la libertad de movimiento, mediante:

- Control de la movilidad

- Control del ambiente físico de la víctima (cautiverio, medidas implementadas para prevenir o evitar el escape)

- Control psicológico

- Control de la sexualidad

- Afirmación de exclusividad

- Sometimiento a tratos crueles

- $\quad$ Trabajos forzados ${ }^{121}$

- $\quad$ No es un requisito para la configuración del tipo la duración.

- Los periodos de tiempo exactos no requieren ser probados más allá de la duda razonable debido al contexto específico de guerra donde los crímenes concernientes ocurrieron.

2. Que el autor haya hecho que esa persona realizara uno o más actos de naturaleza sexual.

En relación con este elemento, debe precisarse que "la violencia sexual no se limita a la invasión física del cuerpo humano y puede incluir actos que no involucran penetración o contacto físico" $" 122$.

A la luz de lo anterior puede establecerse que el tipo penal de esclavitud sexual o prostitución forzada consagrado en el artículo 141 del Código Penal, que exige como conducta típica el "obligar a la víctima a prestar servicios sexuales", al no contemplar

120 Ibid, párrafo 435

121 El trabajo forzoso u obligatorio es definido en el artículo $2^{\circ}$ del Convenio sobre el trabajo forzoso, como "todo trabajo o servicio exigido a un individuo bajo la amenaza de una pena cualquiera y para el cual dicho individuo no se ofrece voluntariamente"

122 Tribunal Penal Internacional para Ruanda. El Fiscal vs. Akayesu. Sentencia del 02 de septiembre de 1998. 
el lucro o provecho económico en la tipificación del delito, describe de manera más acertada la práctica que en el derecho internacional se ha denominado esclavitud sexual. Ello no implica que la prostitución forzada no pueda ser judicializada a la luz del mencionado artículo 141, pues como se vio, la prostitución forzada en todo caso constituye una modalidad de esclavitud sexual y en esta medida, esta conducta también puede adecuarse a lo dispuesto en dicha norma.

\section{CONCLUSIONES}

A la luz de la normativa, jurisprudencia y doctrina internacionales, la esclavitud sexual es un crimen de lesa humanidad y un crimen de guerra que comprende por lo menos dos elementos constitutivos: i) el ejercicio de los atributos del derecho de propiedad sobre una persona (uso, usufructo y disposición); y ii) la realización de actos de naturaleza sexual bajo este contexto.

Por su parte, la prostitución forzada constituye una forma de esclavitud sexual que consiste en el usufructo de la persona obligándola a prestar servicios sexuales a cambio de los cuales el autor de la conducta u otra persona obtienen o esperan obtener ventajas pecuniarias o de otro tipo.

Estas definiciones tienen fundamento en fuentes de derecho como las Convenciones sobre la Esclavitud (1926 y 1957), los Elementos de Crímenes de la Corte Penal Internacional y algunas decisiones judiciales de tribunales internacionales, cuya validez interpretativa ha sido reconocida por la Corte Constitucional.

De esta manera, estas definiciones se convierten en criterio de interpretación del artículo 141 del Código Penal Colombiano, el cual penaliza bajo una misma descripción típica las conductas de esclavitud sexual y prostitución forzada, resultando confuso su alcance punitivo.

Las fuentes normativas, jurisprudenciales y doctrinarias estudiadas en el documento, complementan la definición contenida en el mencionado artículo 141, de acuerdo con el cual tanto la prostitución forzada como la esclavitud sexual consisten en la prestación forzosa de servicios sexuales.

Como se ve, la descripción típica citada no contempla la obtención del lucro o provecho económico o de otro tipo como elemento constitutivo del delito, por lo cual puede concluirse que la misma se ajusta de manera más adecuada a la definición internacional del crimen de esclavitud sexual. No obstante, al ser la prostitución forzada una forma de esclavitud sexual, el artículo 141 del Código Penal sirve para sancionar las dos conductas. 


\section{REFERENCIAS}

\section{Doctrina Nacional}

Caicedo Delgado, L., Buenahora Streithorst, N., Benjumea Rúa, A. (2009). Guía para llevar casos de violencia sexual. Propuestas de argumentación para enjuiciar crímenes de violencia sexual cometidos en el marco del conflicto armado colombiano. Corporación Humanas - Centro Regional de Derechos Humanos y Justicia de Género.

Olásolo Alonso, H. (2009). "Ensayos sobre la Corte Penal Internacional". Pontificia Universidad Javeriana, Medellín, Biblioteca Jurídica Dike.

Valencia Villa, A. (2007). "Derecho Internacional Humanitario. Conceptos básicos. Infracciones en el conflicto armado colombiano".

\section{Doctrina Internacional}

Comité Internacional de la Cruz Roja (2001), Comentario del Protocolo Adicional I a los Convenios de Ginebra de 1949, tomo II. Plaza \& Janes Editores. Colombia.

Diccionario de la Lengua Española, vigésima segunda edición, disponible en http://www.rae.es/rae.html.

McDougall, Gay J. (2000). “Formas contemporáneas de la esclavitud. La violación sistemática, la esclavitud sexual y las prácticas análogas a la esclavitud en tiempo de conflicto armado" (informe final presentado como relatora especial), Naciones Unidas - Consejo Económico y Social, E/CN.4/Sub.2/2000/21.

Salmón, E. (2004). Introducción al Derecho Internacional Humanitario. Instituto de Democracia y Derechos Humanos de la Pontificia Universidad Católica del Perú y Comité Internacional de la Cruz Roja. Fondo Editorial de la Pontificia Universidad Católica del Perú.

\section{Normativa colombiana}

Constitución Política de Colombia, 1991.

Ley 360 de 1997. Diario Oficial No. 42978 del 11 de febrero de 1997. Por medio de la cual se modifican algunas normas del título XI del Libro II del Decreto-ley 100 de 1980 (Código Penal), relativo a los delitos contra la libertad y pudor sexuales, y se adiciona el artículo 417 del Decreto 2700 de 1991 (Código Procedimiento Penal) y se dictan otras disposiciones.

Ley 599 de 2000. Diario Oficial No. 44.097 de 24 de julio del 2000. Por medio de la cual se expide el Código Penal.

Ley 742 de 2002. Diario Oficial No. 44.826 del 7 de junio de 2002. Por medio de la cual se aprueba el Estatuto de Roma de la Corte Penal Internacional. 
Ley 782 de 2002. Diario Oficial No. 45.043 del 23 de diciembre de 2002. Por medio de la cual se prorroga la vigencia de la Ley 418 de 1997, prorrogada y modificada por la Ley 548 de 1999 y se modifican algunas de sus disposiciones.

Ley 975 de 2005. Diario Oficial No. 45980 del 25 de julio de 2005. Por la cual se dictan disposiciones para la reincorporación de miembros de grupos armados organizados al margen de la ley, que contribuyan de manera efectiva a la consecución de la paz nacional y se dictan otras disposiciones para acuerdos humanitarios.

Ley 1268 de 2008. Diario Oficial No. 47.219 del 31 de Diciembre de 2010. Por medio de la cual se aprueban las "reglas de procedimiento y prueba" y los "elementos de los crímenes de la Corte Penal Internacional”.

\section{Instrumentos internacionales}

Convención sobre la esclavitud (1926)

Convenio relativo al trabajo forzoso u obligatorio (1930)

Convención suplementaria sobre la abolición de la esclavitud, la trata de esclavos y las instituciones y prácticas análogas a la esclavitud (1956)

Estatuto de Roma de la Corte Penal Internacional (1998). A/CONF.183/9.

Elementos de los Crímenes del Estatuto de Roma de la Corte Penal Internacional (2002). ICC-ASP/1/3.

\section{Jurisprudencia colombiana}

\section{Corte Constitucional}

Sentencia C-574 de 1992. Magistrado Ponente: Ciro Angarita Barón.

Sentencia C-295 de 1993. Magistrado Ponente: Carlos Gaviria Díaz.

Sentencia C-531 de 1993. Magistrado Ponente: Eduardo Cifuentes Muñoz.

Sentencia C-179 de 1994. Magistrado Ponente: Carlos Gaviria Díaz.

Sentencia C-038 de 1995. Magistrado Ponente: Alejandro Martínez Caballero.

Sentencia C-225 de 1995. Magistrado Ponente: Alejandro Martínez Caballero.

Sentencia C-423 de 1995. Magistrado Ponente: Fabio Morón Díaz.

Sentencia C-578 de 1995. Magistrado Ponente: Eduardo Cifuentes Muñoz.

Sentencia C-092 de 1996. Magistrado Ponente: Eduardo Cifuentes Muñoz.

Sentencia C-135 de 1996. Magistrados Ponentes: Eduardo Cifuentes Muñoz, Alejandro Martínez Caballero y Jorge Arango Mejía.

Sentencia C-013 de 1997. Magistrado Ponente: José Gregorio Hernández Galindo. Sentencia C-040 de 1997. Magistrado Ponente: Antonio Barrera Carbonell. 
Sentencia C-237 de 1997. Magistrado Ponente: Carlos Gaviria Díaz.

Sentencia C-291 de 1997. Magistrado Ponente: Manuel José Cepeda Espinosa.

Sentencia C-327 de 1997. Magistrado Ponente: Fabio Morón Díaz.

Sentencia C-359 de 1997. Magistrado Ponente: Jorge Arango Mejía.

Sentencia C-156 de 1999. Magistrado Ponente: Martha Victoria Sáchica Méndez.

Sentencia SU-256 de 1999. Magistrado Ponente: José Gregorio Hernández Galindo.

Sentencia C-559 de 1999. Magistrado Ponente: Alejandro Martínez Caballero.

Sentencia T-568 de 1999. Magistrado Ponente: Carlos Gaviria Díaz.

Sentencia C-840 de 2000. Magistrado Ponente: Carlos Gaviria Díaz.

Sentencia C- 774 de 2001. Magistrado Ponente: Rodrigo Escobar Gil.

Sentencia C-181 de 2002. Magistrado Ponente: Marco Gerardo Monroy Cabra.

Sentencia C- 226 de 2002. Magistrado Ponente: Álvaro Tafur Galvis.

Sentencia C-420 de 2002. Magistrado Ponente: Jaime Córdoba Triviño.

Sentencia C-578 de 2002. Magistrado Ponente: Manuel José Cepeda Espinosa.

Sentencia C-762 de 2002. Magistrado Ponente: Rodrigo Escobar Gil.

Sentencia C-1076 de 2002. Magistrado Ponente: Clara Inés Vargas Hernández.

Sentencia C-205 de 2003. Magistrado Ponente: Clara Inés Vargas Hernández.

Sentencia C-148 de 2005. Magistrado Ponente: Álvaro Tafur Galvis.

Sentencia C-291 de 2007. Magistrado Ponente: Manuel José Cepeda Espinosa.

Sentencia T-458 de 2007. Magistrado Ponente: Álvaro Tafur Galvis.

Sentencia C-801 de 2009. Magistrado Ponente: Gabriel Eduardo Mendoza Martelo.

\section{Corte Suprema de Justicia, Sala de Casación Penal}

Proceso No. 9401, Sentencia del 08 de mayo de 1996. Magistrado Ponente: Fernando Arboleda Ripoll.

Proceso No. 25.743, Sentencia del 26 de octubre de 2006. Magistrado Ponente: Álvaro Orlando Pérez Pinzón.

Proceso No. 20.413, Sentencia del 23 de enero de 2008. Magistrado Ponente: Julio Enrique Socha Salamanca.

Proceso No. 21.691, Sentencia del 17 de septiembre de 2008. Magistrado Ponente: Javier Zapata Ortíz.

Proceso No. 25.578, Sentencia del 08 de octubre de 2008. Magistrado Ponente: Julio Enrique Socha Salamanca. 
Proceso No. 31.539, Auto del 31 de Julio de 2009. Magistrado Ponente: Augusto Ibáñez Guzmán.

Proceso No. 32.022, Auto del 21 septiembre de 2009, Magistrado Ponente: Sigifredo Espinosa Pérez.

Proceso No. 23.508, Sentencia del 23 de septiembre de 2009. Magistrado Ponente: Julio Enrique Socha Salamanca. 
